\title{
Laser Surface Treatments of Aluminum Alloys
}

\author{
Reza Shoja Razavi and Gholam Reza Gordani \\ Materials Science and Engineering Department, Malek Ashtar University of Technology, \\ Shahin Shahr, \\ Iran
}

\section{Introduction}

Advanced industrial applications require materials with special surface properties such as high corrosion and wear resistance and hardness. Alloys possessing these properties are usually very expensive and their utilization drastically increases the cost of the parts. On the other hand, failure or degradation of engineering components due to mechanical and chemical/electrochemical interaction with the surrounding environment is most likely to initiate at the surface because the intensity of external stress and environmental attack are often highest at the surface.

The engineering solution to prevent or minimize such surface region of a component through a procedure known as surface engineering. Conventionally practiced surface engineering techniques like carburizing, nitriding, etc. are often material specific, time/energy/manpower intensive and lacking in precision.

Among the surface engineering techniques, a relatively new and attractive method is laser surface treatment. In other words, laser surface treatment offers an excellent scope for tailoring the surface microstructure and/or composition of a component and proves superior to conventionally surface engineering.

For most engineering application, the laser, in simple terms, can be regarded as a device for producing a finely controllable energy beam, which, in contact with a material, generates considerable heat. The basic physics of laser surface treatment is simply heat generation by laser interaction with the surface of an absorbing material and subsequent cooling either by heat conduction into the interior, or by thermal reradiation at high temperatures from the surface of the material. Various laser surface treatment methods that are currently available are shown in figure 1.

\section{Laser - assisted materials surface treatment requirements}

Figure 2 shows general regimes of various laser surface treating parameters for both pulsed and continuous wave lasers. Short pulses (ns to fs) with high peak power densities are desirable for laser shock processing and ablation applications. In general, longer pulses $\left(\mu_{\mathrm{s}}\right.$ to $\mathrm{ms}$ ) or continuous wave lasers are preferred for melting and heating processes (Nagarathnam \& Taminger, 2001).

Laser chemical vapor deposition and laser surface transformation hardening require lower densities and interaction times as compared to processes involving meting and vaporization. 


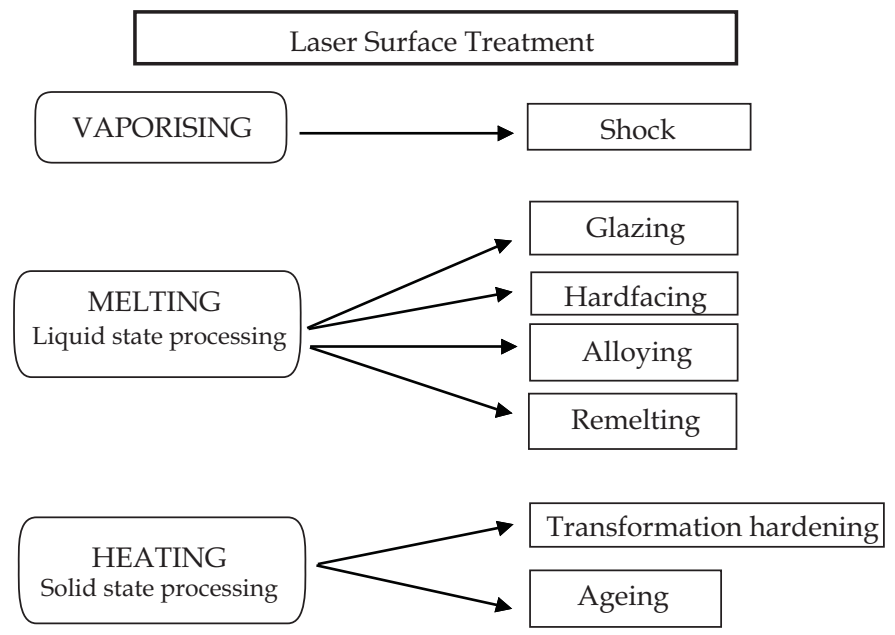

Fig. 1. Various laser surface treatment methods

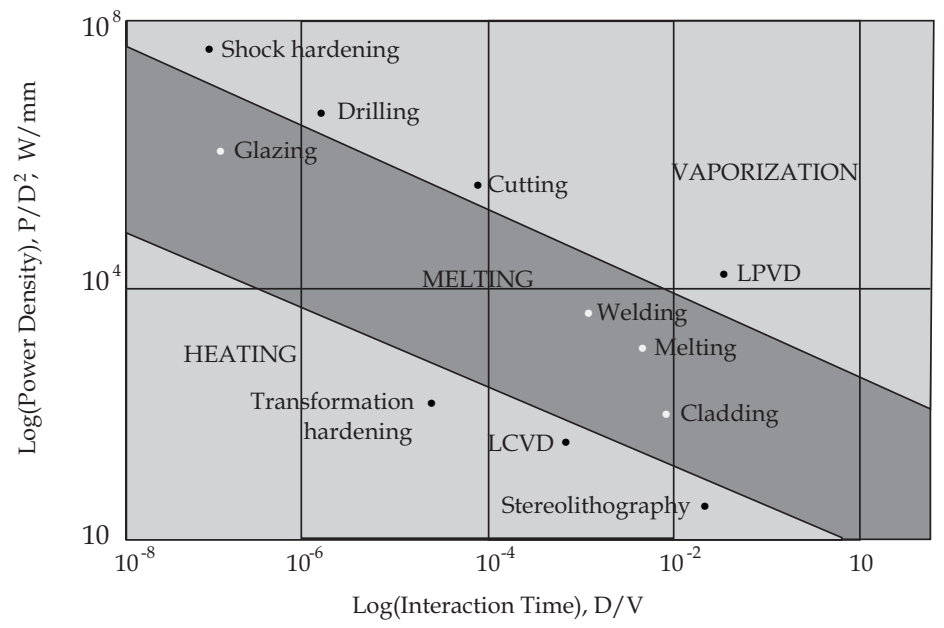

Fig. 2. Laser power density, specific energy and interaction times for various laser processing regimes (Nagarathnam \& Taminger, 2001)

\section{Laser surface alloying of aluminium alloys}

Laser surface alloying (LSA) involves tailoring the surface microstructure and composition by rapid melting, intermixing and solidification of a pre/co deposited surface layer with apart of the underlying substrate (Majumdar \& Manna, 2002 ). Also in this treatment, a shallow layer at the surface of the material is melted by the laser beam which becomes efficiently coupled to the surface, while alloying elements are added simultaneously to give a local composition having the desired surface properties on solidification (Renk et al., 1998). When alloying elements are added to the melted pool then they will start to 
interdiffuse into the substrate. As soon as the laser pulse is finished the resolidification process begins from the liguid/solid interface towards the surface.

Laser surface alloying may induce an extreme heating/cooling rate of $10^{4}-10^{11} \mathrm{k} / \mathrm{s}$, thermal gradient of $10^{5}-10^{8} \mathrm{k} / \mathrm{m}$ and solidification velocity as high as $30 \mathrm{~m} / \mathrm{s}$ (Draper \& Poate, 1985). Due to the high cooling rates, solid state diffusion can be neglected and homogeneous and fine solidification microstructures can be achieved with a wide variety of surface compositions without the limitations of conventional processes, for instance, to extend solid solutions and to obtain metastable structures or even metallic glasses (Damborenea, 1998). Laser surface alloying of Al- alloys by different alloying elements and different techniques was investigated by several researchers. In most of their reports, it was shown that the structure of the zones of laser alloyed depends on the properties of the treated and alloying materials and on the dispersity of the alloying particles, the power of the laser radiation, and the duration of the irradiation (Aleksandrov, 2002). Figure 3 shows the structure of Al-alloy D16 saturated with $\mathrm{NiO}_{2}$ and $\mathrm{NbSi}_{2}$ particles. The saturation with $\mathrm{NiO}_{2}$ is provided by convective mass transfer, which is confirmed by the vortex-like appearance of the structure of the molten zone (figure 3a). The well-manifested heterophase (figure $3 b$ ) in the surface layer is provided by the mechanism of penetration of particles of $\mathrm{NbSi}_{2}$ into the molten pool.
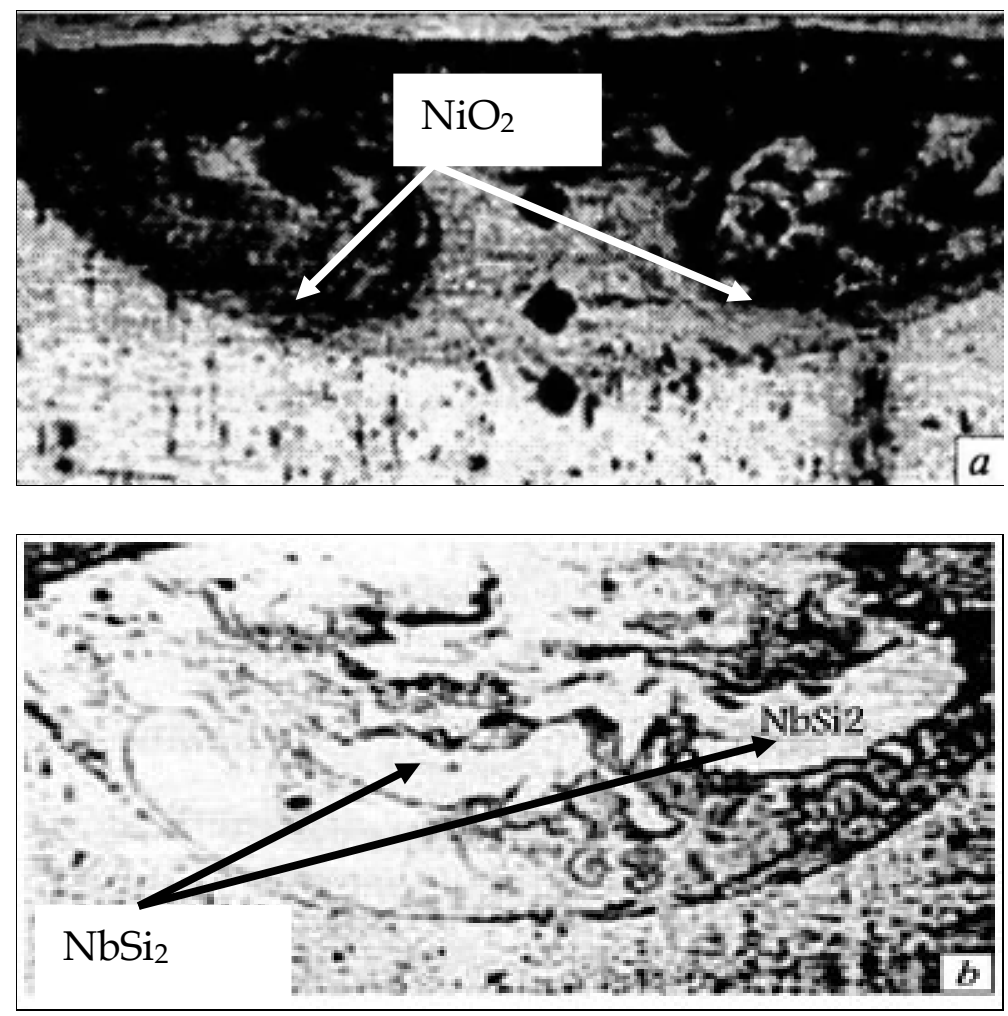

Fig. 3. Structure of the molten zone after laser alloying of Al-alloy D16 with $\mathrm{NiO}_{2}$ (a) and $\mathrm{NbSi}_{2}$ (b). x200. (Aleksandrov, 2002) 
The structure of the laser surface alloyed of $\mathrm{Al}$ with $\mathrm{Nb}$ is shown in figure 4 (Almeida et al., 2001). A strong segregation of $\mathrm{Nb}$ in structure leading to the formation of a zone of resolidified $\mathrm{Al}$ solid solution and a zone with a high $\mathrm{Nb}$ concentration, consists of dendrites of $\mathrm{Nb}$-free $\alpha-\mathrm{Al}$ solid solution and undissolved particles of $\mathrm{Nb}$ (figure $4 \mathrm{a}$ ), that some of these particles can be surrounded by a layer consisting of $\mathrm{Al}_{3} \mathrm{Nb}$ dendrites in an $\alpha-\mathrm{Al}$ matrix (figure $4 \mathrm{~b}$ ) showing incipient dissolution and partial redistribution of $\mathrm{Nb}$ due to convective flow. It is necessary to mentioned that the temperature and convective mass transport must be sufficient to allow for the complete homogenization of the alloyed layers. This, it can be seen in figure 4 that the temperature and convective mass transport were not sufficient to allow for the complete homogenization of the material (Almeida et al., 2001).

Mazumder (Majumdar \& Manna, 2002) studied mass transport in melt pools using a numerical model and concluded that the extremely fast homogenization frequently observed in laser surface alloying can only be explained by the intense Marangoni convection caused by the high temperature gradients within the melt pool (Almeida et al., 2001), with diffusion having only a minor role.
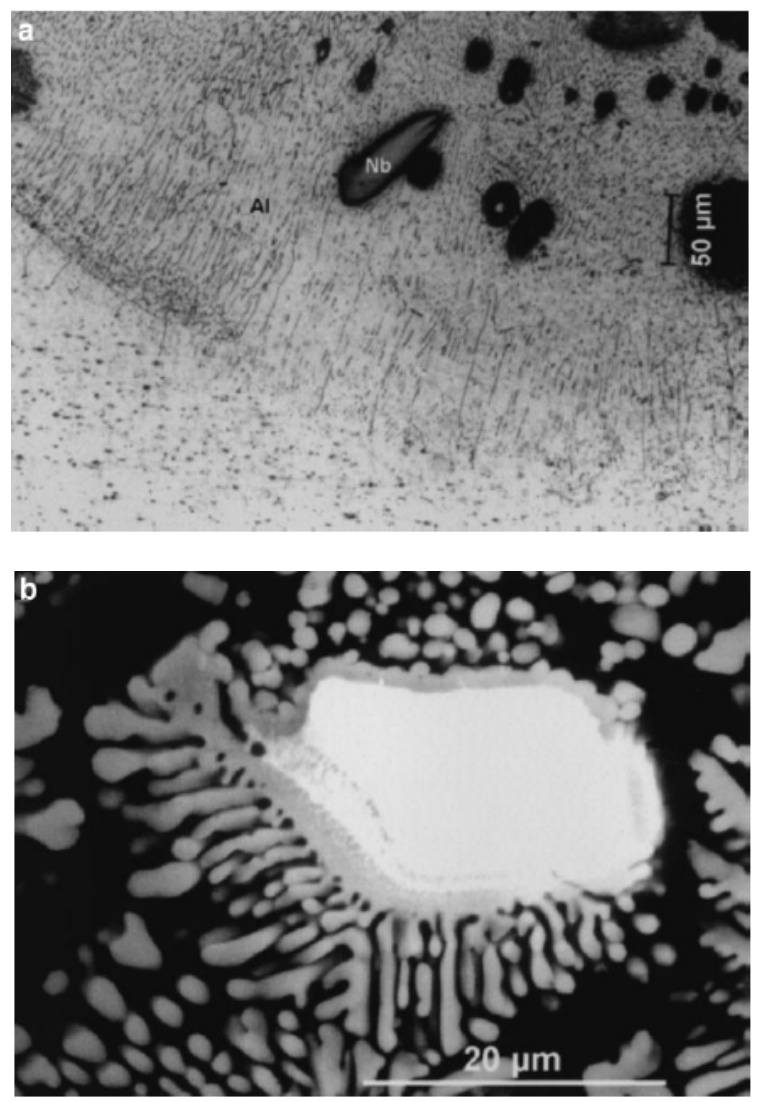

Fig. 4. (a) Structure of the bottom layer (A). (b) Undissolved $\mathrm{Nb}$ particle surrounded by a layer of $\mathrm{Al}_{3} \mathrm{Nb}$ dendrites and $\alpha-\mathrm{Al}$ (Almeida et al., 2001) 
They suggested that the influence of convection in liquid homogenization could be characterized by the surface tension number, $S$, which relates thermocapillarity-induced convection velocity and laser beam scanning speed, and is give by:

$$
s=\frac{(d \sigma / d T) q d}{\mu u_{0} k}
$$

Where $(\mathrm{d} \sigma / \mathrm{dT})$ is the temperature coefficient of the surface tension, $\mathrm{q}$ is the net heat flow from the laser beam, $d$ is diameter of the laser beam, $\mu$ is the viscosity, $u_{0}$ is the scanning speed of the laser beam, and $k$ is the thermal conductivity. When $S$ is low $(S \leq 45000)$, convection is negligible. Due to the short lifetime of the melt pool, mass transport will be insufficient for melt homogenization. When $\mathrm{S}$ is high, convection plays a dominant role in transport phenomena in the melt pool. In general for metals, the convection speed is several orders of magnitude higher than the scanning speed, leading to rapid homogenization. However, for liquid $\mathrm{Al}$ the temperature coefficient of the surface tension $(\mathrm{do} / \mathrm{dT})$ is relatively low $\left(-0.155 \times 10^{-3} \mathrm{Nm}^{-1} \mathrm{k}^{-1}\right)$, and therefore $S$ will be low. Consequently, in some cases insufficient homogenization of the melt pool is to be expected for laser surface alloying of Al-alloys. For example, this was happened for recently mentioned Almeida's research that is shown in figure 4 (Almeida et al., 2001). A further difficulty arises when the alloying elements react with the melt pool material to form insoluble high melting temperature phases, such as intermetallic compounds. In the matter the diffusion phenomena is responsible to control of dissolution kinetics.

The dissolution kinetics was theoretically analysed by Costa and Vilar (Costa \& Vilar, 1996) using a spherical geometry and dropping the quasi-steady-state approximation. Figure 5 shows the results of evaluation of intermetallic layer thickness of $\mathrm{Al}_{3} \mathrm{Nb}$ as a function of time. This result is reported by Almeida and co-workers (Almeida et al., 2001). They calculated the dissolution time of $\mathrm{Nb}$ particles with a diameter of $100 \mu \mathrm{m}$. These particles takes about $22 \mathrm{~s}$ to transform to $\mathrm{Al}_{3} \mathrm{Nb}$, a time much longer than the interaction time used $(0.24 \mathrm{~s})$ in their research.

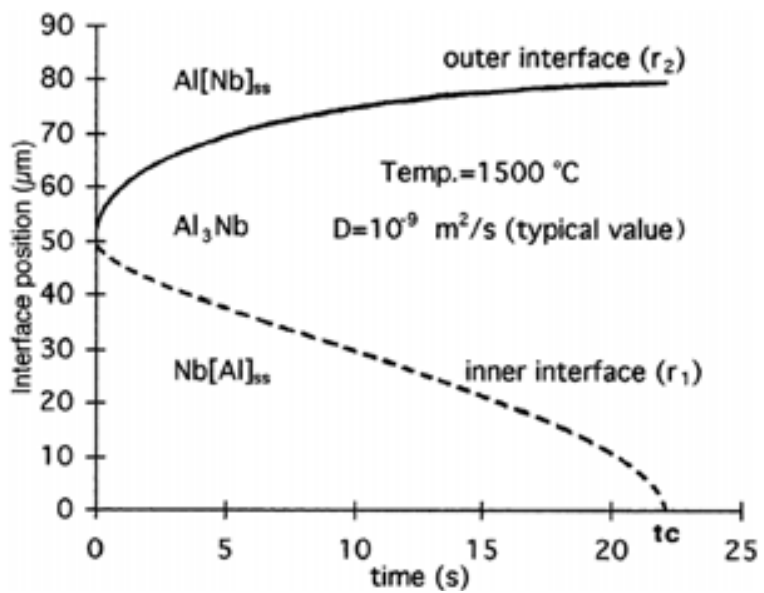

Fig. 5. Thickness of intermetallic layer and size of particle for any laser interaction time (Almeida et al., 2001) 
In order to obtain significant particle dissolution, the temperature of the melt pool must be higher than the melting point of the intermetallic compounds.

Since convection-driven homogenization is negligible, and the melting point of alloying elements is higher than the melting temperature of $\mathrm{Al}$, the latter starts to solidify before the alloying particles dissolve, and a layer consists of the starting material will be formed. In general, this happened in the bottom layers. In the upper layers, due to the higher temperature of the melt, the alloying particles dissolve in the liquid $\mathrm{Al}$.

The microstructure of alloyed layer depends on solidification rate $(R)$ and the temperature gradient at the solid-liquid interface $(\mathrm{G})$ which in turn depend on heat and mass transfer in the system (Almeida et al., 2001). A simple relation exists between the local solidification rate $(R)$ and the scanning speed gives by fallow equation:

$$
\mathrm{R}=\mathrm{V}_{\mathrm{S}} \cos \theta
$$

where $\theta$ is the angle between the normal to the solid-liquid interface and the scanning direction. The solidification rate increases with decreasing depth from 0 at the bottom of the melt pool $(\cos \theta=0$ at this point) to a value that remains lower that the scanning speed, because $\cos \theta<1$. Conversely, the thermal gradient $G$ is higher at the bottom of the melt pool and decreases as depth decreases. Both solidification parameters vary rapidly during the first stages of solidification (near the bottom of the melt pool) to reach a value that remains approximately constant during most of the solidification process. Consequently, the microstructure in most of the re-solidified layer can be characterized by a single set of solidification parameters and should not change significantly.

Sometimes, in laser surface alloying the microstructure of alloyed layer appears as a texture. The texture effect increases with increasing solidification speed. The origin of this texture can be understood by considering the solidification mechanism in laser surface alloying and the variation of the shape of the melt pool as a function of scanning speed.

Gingo and et. al (Gingu et al., 1999) produced $\mathrm{Al} / \mathrm{SiC}_{\mathrm{p}}$ composite by laser surface alloying. Figure 6 presents the microstructural aspect of the alloyed layer produced at the surface of an AA413 alloy. There is an obvious difference between the base microstructure of the Al alloy, which is the classic eutectic AlSi12, characterised by dendrites grains dispose randomly in the eutectic mass (zone 1), and the very fine granulated microstructure of the alloyed layer (zone2).

In this process, depending on the processing parameters, it is possible to use or not use an adhesive layer at the material support. As can be seen in figure 7, in this case there is a perfect adherence of the alloyed layer at the AA413 support; this phenomenon can be explained by the perfect compatibility of the matrix of Al- alloy (Gingu et al., 1999).

In laser surface alloying of $\mathrm{Al}$ with $\mathrm{Nb}$ as an alloying element, the dendritic structure was observed by Almeida et. al (Almeida et al., 2001), showing that $\mathrm{Al}_{3} \mathrm{Nb}$ grows with a dendritic solid/liquid interface. In this type of growth, there is a preferential growth direction usually a low index crystallographic direction. During the initial stages of solidification competition between neighboring dendrites with different orientations occurs, and those with the preferential growth direction nearest to the heat flow direction will be favored, leading to preferential orientation, and eventually to a strong texture. When the scanning speed of surface is increased the shape of melt pool increasingly elongated from semi-hemispherical. Also, when the scanning speed is low the heat flow direction changes progressively from the fusion line to the surface, leading to a variety of preferential growth directions of columnar grains (Almeida et al., 2001). 


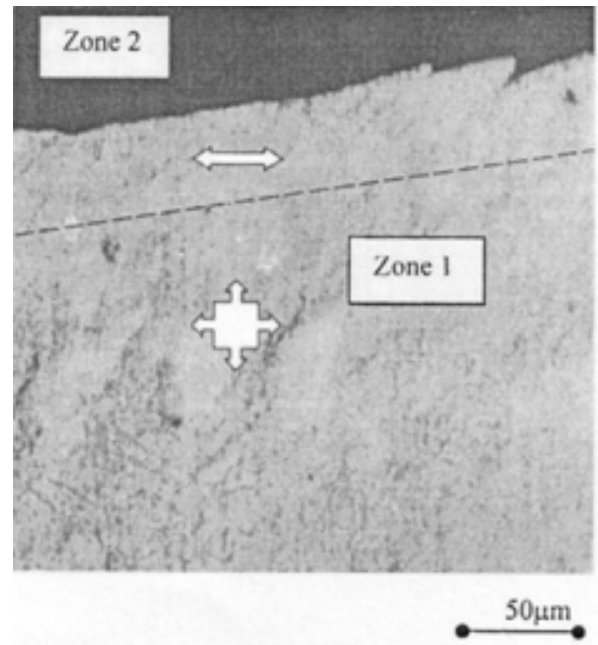

Fig. 6. The micro structural aspects of the laser alloyed layer (Gingu et al., 1999)

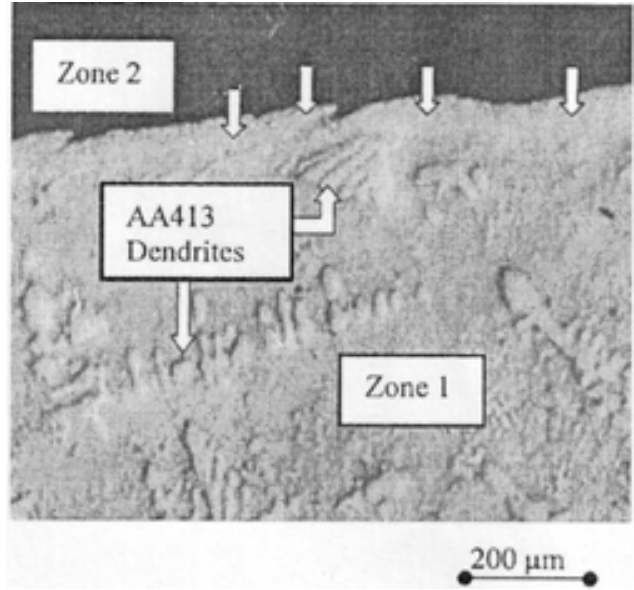

Fig. 7. The adherence aspect of the layer at the material support (Gingu et al., 1999)

A mathematical modeling of laser surface alloying with solid particles is established by Aleksandrov (Aleksandrov, 2002). According to this model, the presence of a transverse temperature gradient $\frac{\partial T}{\partial X}$ makes the particles move to the peripheral part of the molten pool. In the case of low gradients $\frac{\partial T}{\partial X}$ and $\frac{\partial T}{\partial Z}$ the particles simply drown in the field of the effective force of gravity (with allowance for the buoyancy force). The higher the difference in the densities of the alloying and Al alloys, the more effective the immersion of the particles. The equations of the motion of a single particle in Cartesian coordinates $\mathrm{X}, \mathrm{Z}$ have the form (Aleksandrov, 2002): 


$$
\begin{gathered}
\frac{4}{3} \pi p R^{2} \ddot{x}=2 \alpha_{0} \frac{\partial T}{\partial x} R-6 \pi \eta R \dot{x} \\
\frac{4}{3} \pi p R^{3} \ddot{z}=2 \alpha_{0} \frac{\partial T}{\partial z} R+\frac{4}{3} \pi\left(P-P_{1}\right) R^{3} g-6 \pi \eta R \dot{z}
\end{gathered}
$$

where $\rho$ is the density of the particle, $\mathrm{R}$ is the radius of the particle, $\rho_{1}$ is the density of the $\mathrm{Al}$ alloy, $\eta$ is the viscosity of the $\mathrm{Al}$ alloy, $x, \ddot{x}$ are the transverse velocity and acceleration of the particle respectively, and $z, z$ are the vertical velocity and acceleration of the particles, respectively.

The mechanism of the infusion and velocity of particles in melt pool affects on the formation of heterogeneous or homogenous structure in alloyed layer. The corresponding qualitative dependence $v_{0}(R)$ is plotted in figure 8 .

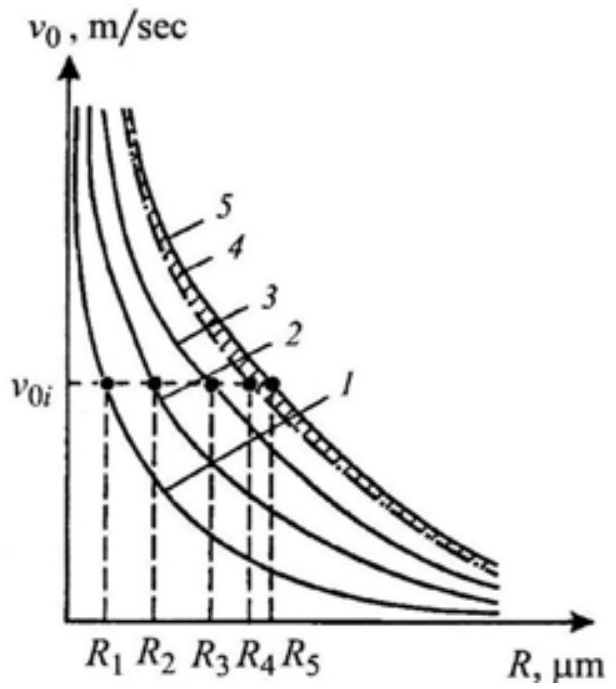

Fig. 8. Dependence of the initial velocity of the particles $v_{0}$ on their radius $R$ at a fixed surface density $\left(\rho_{\mathrm{i}}\right)$ of the energy of laser radiation $\left(\mathrm{P}_{1}<\mathrm{P}_{2}<\mathrm{P}_{3}<\mathrm{P}_{4}<\mathrm{P}_{5}\right)$ (Aleksandrov, 2002)

The order of magnitude of the initial velocity of the particles $v_{0}$ needed for the alloying is determined by the time $\tau$ of the action of laser radiation and the depth of the molten region $\mathrm{H}\left(v_{\mathrm{o}}=\frac{H}{\tau}\right)$. Particles with a size ranging between $\mathrm{R}_{2}$ and $\mathrm{R}_{3}$ may acquire the requisite values $v_{\mathrm{o}}$. Under actual conditions and fixed energy and time of the laser action, the dependences $v_{\mathrm{o}}(\mathrm{R})$ corresponds to a certain domain (hatched in figure 8).

Aleksandrove (Aleksandrov, 2002) also studied the wear resistance of laser surface alloyed layer of $\mathrm{Al}$ alloy with $\mathrm{Ni}, \mathrm{NbSi}_{2}$ and $\mathrm{Cr}$. The results of wear tests are presented in figure 9 .

It can be seen that wear resistance of the hardened surface of aluminum alloy layer is much higher (by factor of 4-5) that the initial one or the one provided by LHT. Also, the friction coefficient tests show that laser surface alloying of $\mathrm{Al}$ alloys with $\mathrm{Cr}, \mathrm{NbSi}_{2}$ and $\mathrm{Ni}$ decreases the friction coefficient of the friction surface by about a factor of 3-4, which makes it possible to vary it by changing the filling factor of the surface and the filling of the alloyed zone with 
conglomerates of high-hardness particles. The use of lubricating materials improves the service properties of various friction pairs (Aleksandrov, 2002). Similar results are reported by Tomlinson and co- workers (Tomlinson \& Bransden, 1996). They studied the effect of laser alloying of metallic elements such as $\mathrm{Si}, \mathrm{Ni}, \mathrm{Fe}, \mathrm{Cu}, \mathrm{Mn}, \mathrm{Cr}, \mathrm{Co}, \mathrm{Mo}$ and $\mathrm{Ti}$ on hypoeutectic cast Al-Si alloys using a pre-placed coating method, and found an improvement in the wear resistance of aluminum. Senthile selvan and co-workers (Senthil Selvan et al., 2000), reported that when laser alloying of $\mathrm{Al}$ with $\mathrm{Ni}$ was carried out at the highest scan speed of $1.1 \mathrm{~m} \mathrm{~min}^{-1}$, the hardness increased to 800-900 $\mathrm{Hv}$ with negligible fluctuations in the hardness behavior. This may be attributed to a uniform LAC with well distributed intermetallic phases. While, at a slightly increased scan speed, the hardness increased from 300 to $800 \mathrm{Hv}$, but with large fluctuations, which can be attributed to the homogeneous alloyed layer (figure 10).

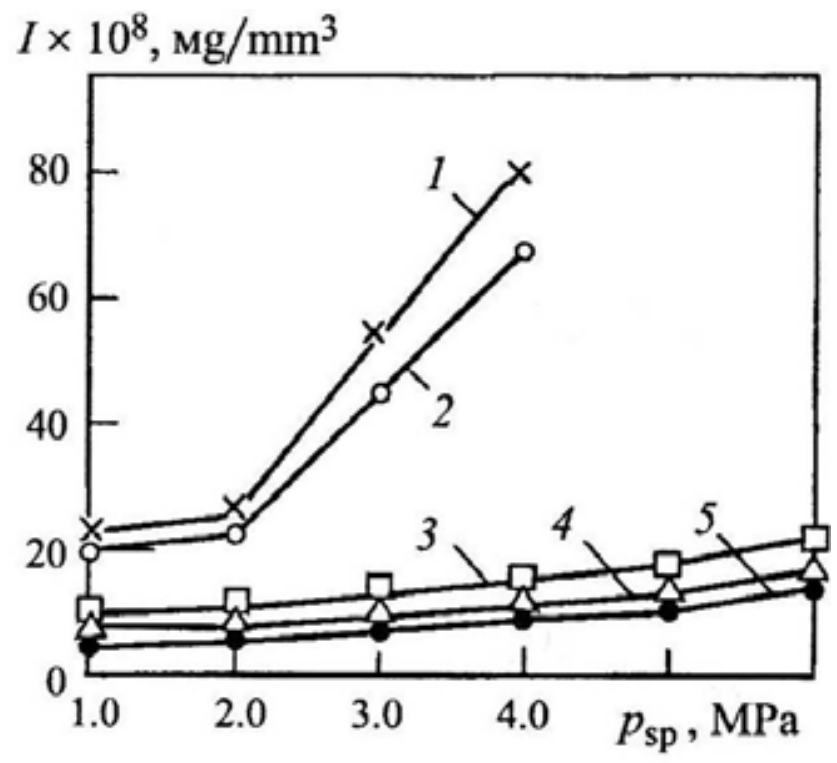

Fig. 9. Dependence of the wear intensity of aluminium alloy on the specific load in a wear test laser treatment at $P=1 \mathrm{kw}, v=12.5 \mathrm{~mm} / \mathrm{sec}, 1)$ Initial state, 2) after LHT 3,4,5) after alloying with $\mathrm{Ni}, \mathrm{NbSi}_{2}, \mathrm{Cr}$, respectively (Aleksandrov, 2002)

The homogeneous distribution of hard intermetallic phases in Al matrix can prevent adhesion and abrasive wear during fretting. Yongqing Fu (Yongqing et al., 1998), reported that after a large number of fretting cycles, the rate of fretting wear depth decreases, which means that the wear volume loss is probably caused by an increase in fretting area rather by wear along the depth. This phenomenon is probably caused by the formation and compaction of fretting oxide debris, which can reduce the wear along the fretting depth. Laser surface alloying can decreases the fretting wear volume by a factor of three and decreases the coefficient of friction, probably due to the hardening effect of oxide debris which can prevent adhesion and abrasive wear during fretting, therefore, it can offers an effective means of preventing fretting wear (figure 11). The (Yongqing et al., 1998). 


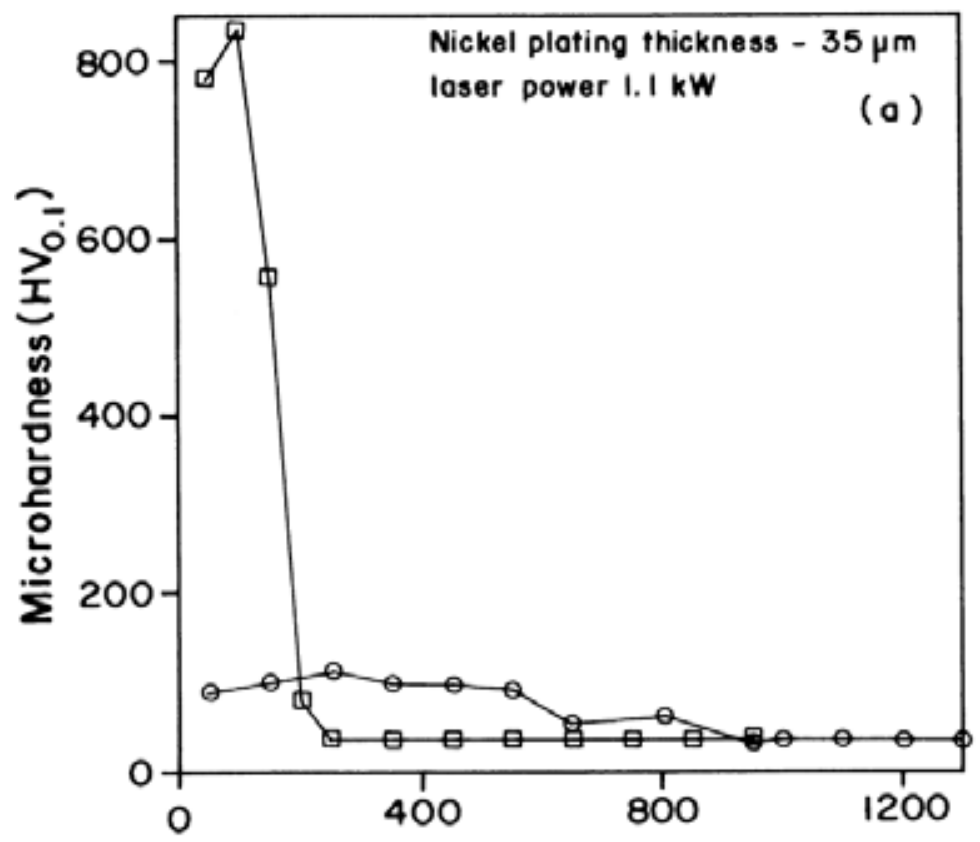

(a)

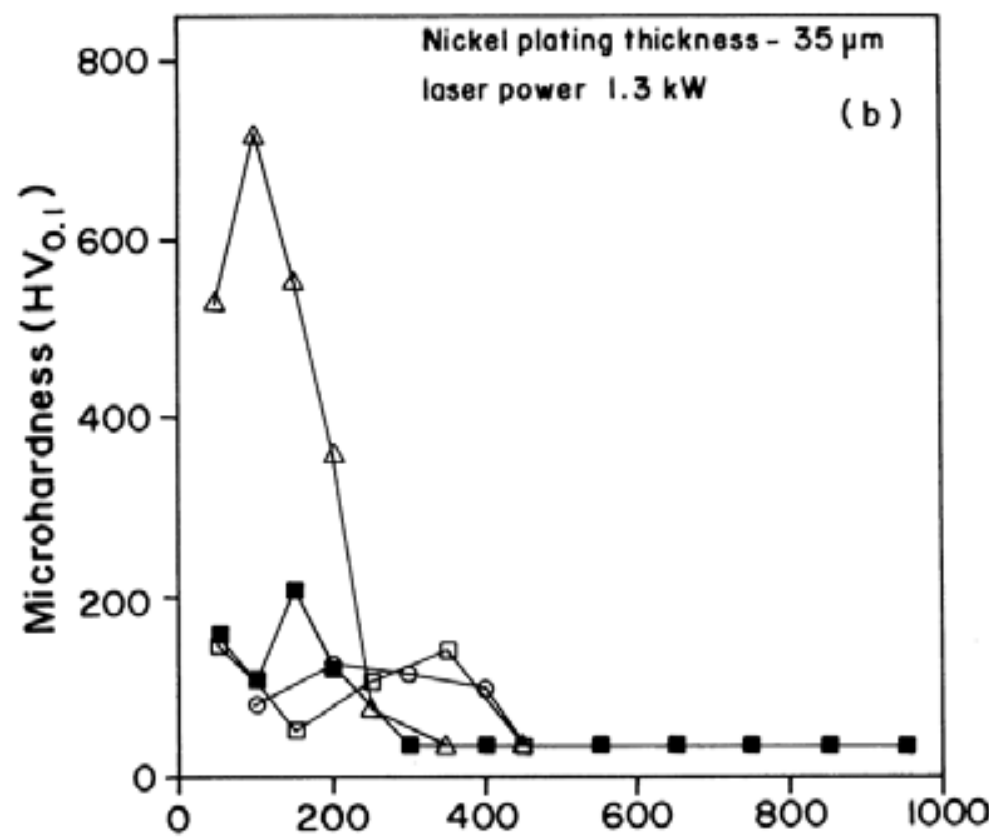

(b) 


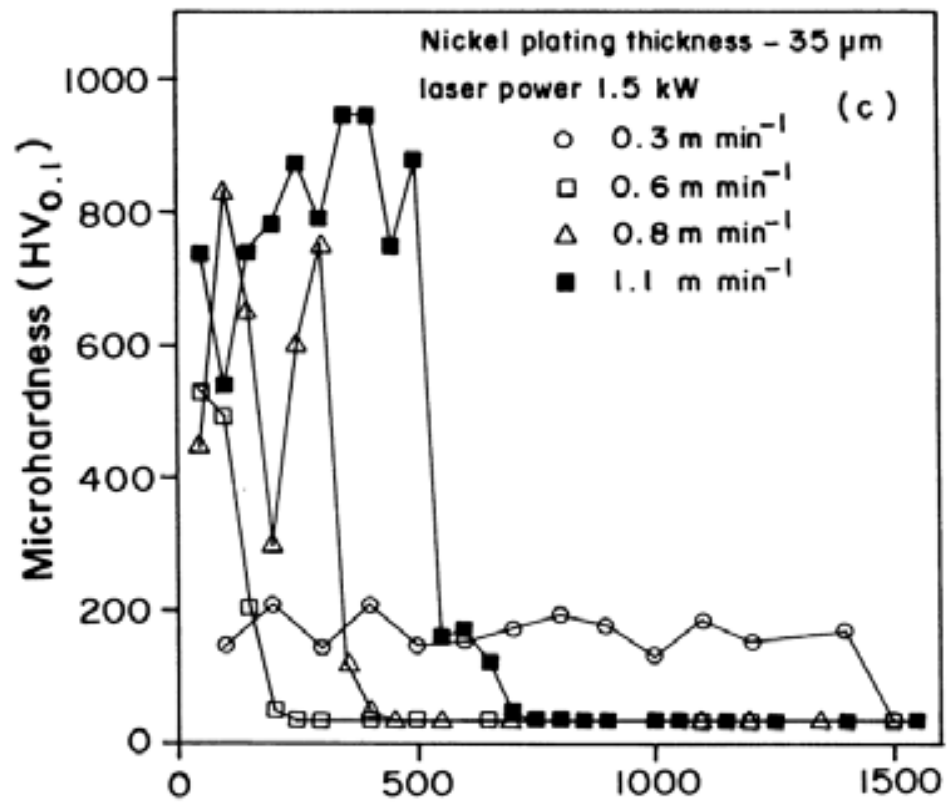

(c)

Fig. 10. Microhardness profiles of laser- alloyed $\mathrm{Cp}$ - $\mathrm{Al}$ with $\mathrm{Ni}$ at powers of a) 1.1, b) 1.3 and c) $1.5 \mathrm{kw}$ at different scan speeds (Senthil Selvan et al., 2001)

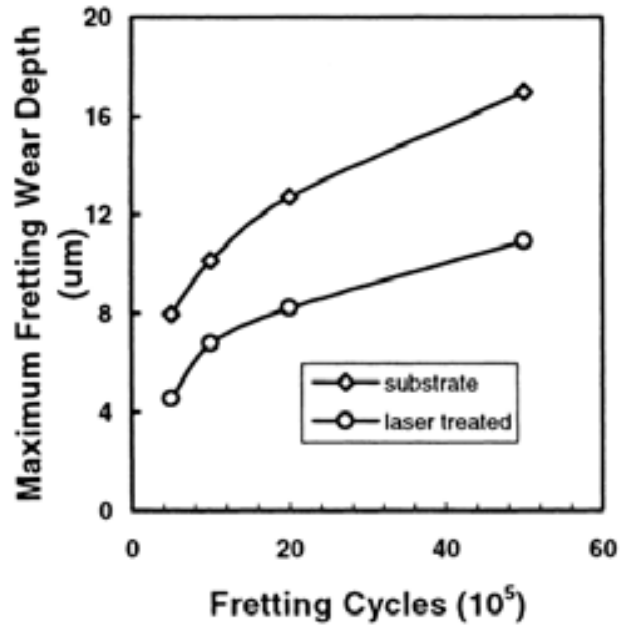

(a) The maximum fretting wear depth

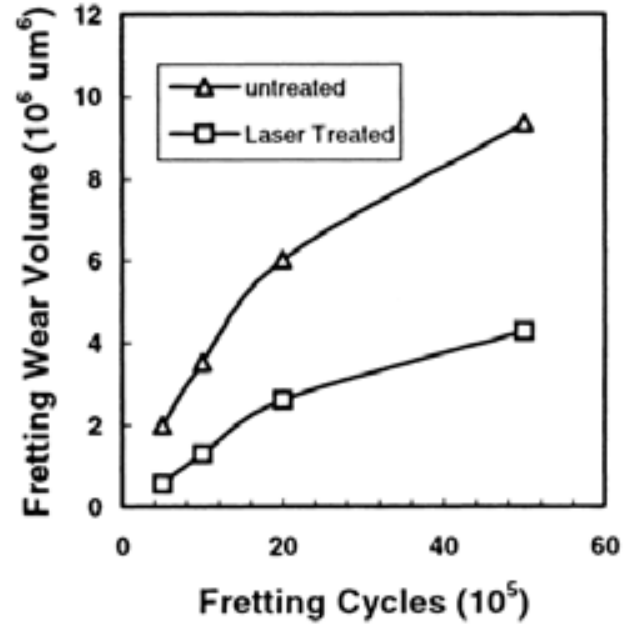

(b) Fretting wear volume

Fig. 11. The maximum fretting wear depth and retting volume for the Al6061 and lasertreated Al- alloy (normal load of $2 \mathrm{~N}$, amplitude of $50 \mu \mathrm{m}$, frequency of $50 \mathrm{~Hz}$ under unlubricated conditions) (Yongqing et al., 1998) 


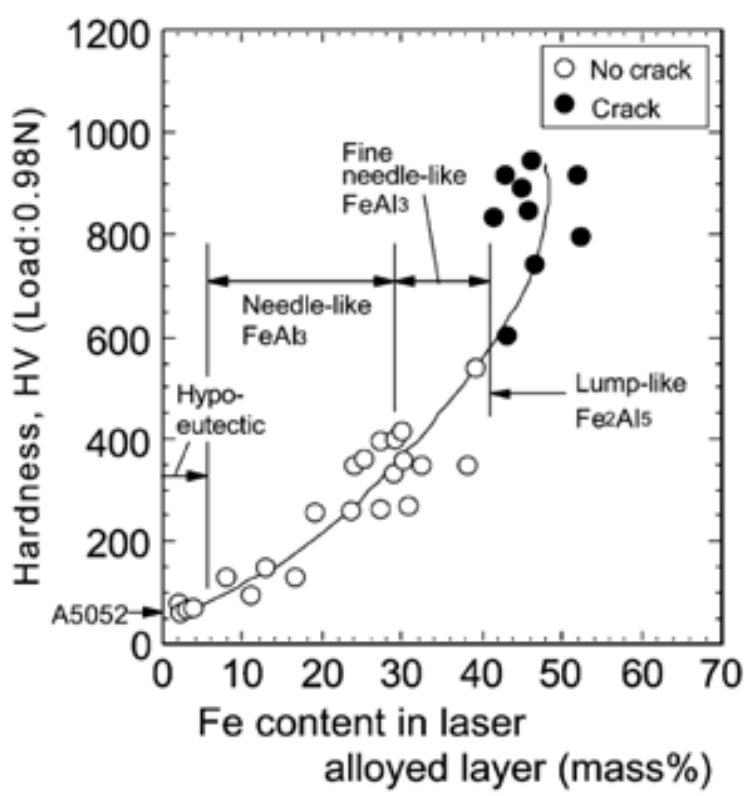

Fig. 12. Relation between Fe content and hardness of laser alloyed layer on aluminum (Tomida \& Nakata, 2003)

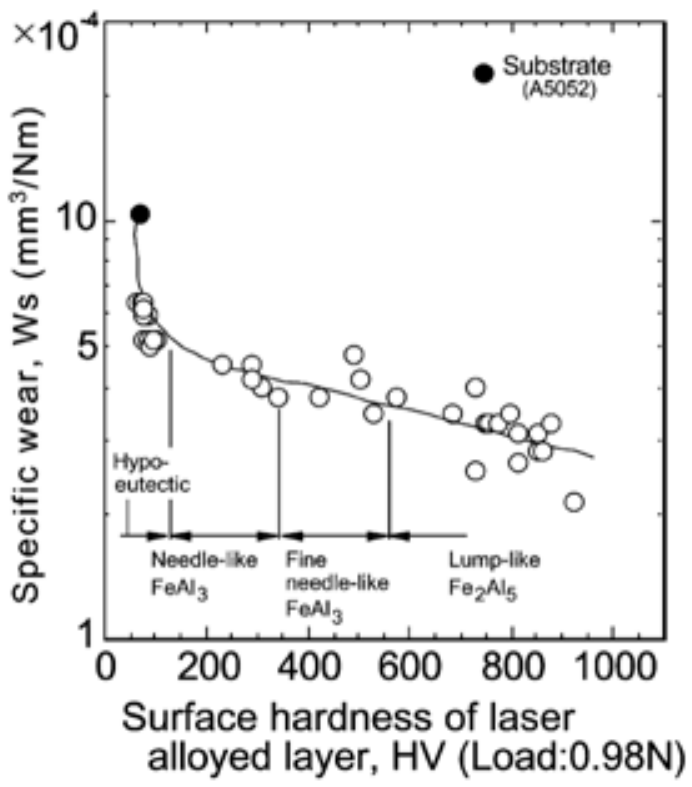

Fig. 13. Relation between surface hardness of laser alloyed layer and abrasive wear behavior. (Tomida \& Nakata, 2003) 
Laser surface alloying of $\mathrm{Al}$ with Fe is studied by Tomida and Nakata (Tomida \& Nakata, 2003). They reported that the hardness of laser alloyed layer increases with increasing Fe content as shown in (Figure 12). However, cracking occurred in the alloyed layer with higher hardness than $\mathrm{Hv} 600$, because the brittle 1ump-like $\mathrm{Fe}_{2} \mathrm{Al}_{5}$ compound was produced in these layers. The wear resistance of the alloyed layer improved with increasing the hardness due to the formation of the fine Fe rich intermetallic compounds. This result is shown in figure 13.

\section{Laser surface remelting of aluminium alloy}

Laser surface melting (LSM) is a well established technology applied to many materials for hardening, reducing porosity and increasing wear and corrosion resistance.

LSM is a versatile and promising technique that can be used to modify the surface properties of a material without affecting its bulk property (Yue et al., 2004; Rams et al., 2007). The modifying in the surface properties of the material is due to rapid melting followed by rapid solidification. The intimate contact between the melt and the solid substrate causes a very fast heat extraction during solidification resulting in very high cooling rates of the order of $10^{5}$ to $10^{8} \mathrm{k} / \mathrm{s}$. The high cooling rates to which this surface layer is submitted result in the formation of different microstructures from bulk metal leading to improved surface properties (Aparecida Pinto et al., 2003). Materials processed via rapid solidification tend to show advantages of refined microstructure, reduced microsegregation, extensive solid solubility and formation of metastable phases (Munitz, 1985; Zimmermann et al., 1989). It is generally accepted that the improvement in corrosion performance is due to refinement/homogenisation of microstructure and dissolusion/redistribution of precipitates or inclusions, which result from rapid solidification (Chong et al., 2003). This was considered to be due to the presence of the compact oxide layers on top of the lasermelted zone. The layers mainly consisted of structures $\alpha-\mathrm{Al}_{2} \mathrm{O}_{3}$, which is a homogeneous and chemically stable phase and serves as an effective barrier to protect the matrix against corrosion attacks. In untreated surfaces of $\mathrm{Al}$ alloys the microsegregation in relatively thin surface layer plays an important role in initiating pitting in the inhomogeneous structures. The schematic of the laser surface melting process is shown in figure 14 (Aparecida Pinto et al., 2003).

Some industrial laser sources such as $\mathrm{CO}_{2}, \mathrm{Nd}: \mathrm{YAG}$, excimer and high power diode lasers were applied to surface melting of aluminium alloys. Since aluminum alloy have no solid phase transformation, if the surface of aluminium alloys should not be melted, the surface cannot be strengthened. In view of the basic physical properties of aluminium alloy, such as large specific heat, high heat conductivity and high reflectivity to laser power density than that for ferrous alloy (Wong et al., 1997). The controlling of laser parameters is very important factor for laser surface melting process.

Because the properties of a material depend largely on its microstructure, controlled formation of such microstructures is essential to develop new materials with desired properties (Aparecida Pinto et al., 2003). Laser parameters such as laser power density, interaction time and scan speed affect on solidification behaviour and thus the microstructure of melted zone can be changed.

The diagram shown in figure 15 associated the microstructural evolution with the solid/liquid front velocity (Aparecida Pinto et al., 2003). 


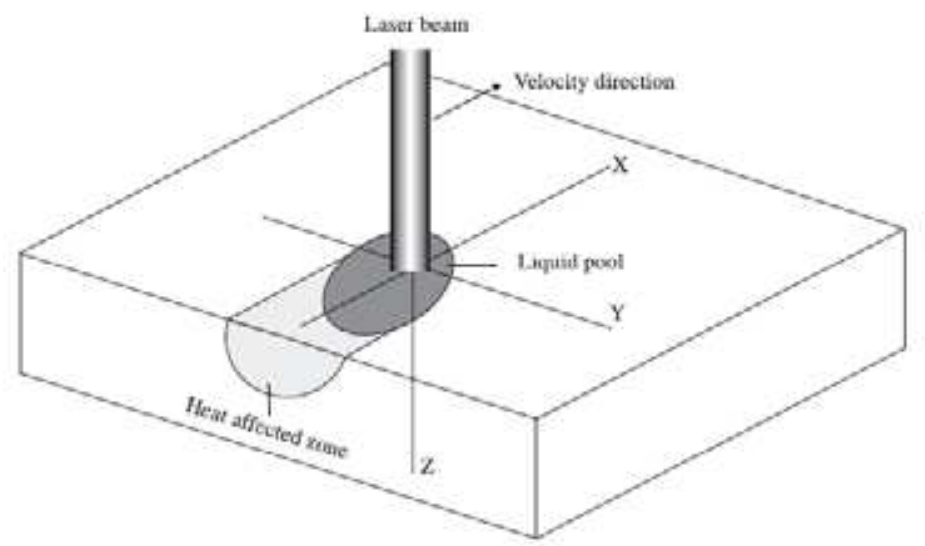

Fig. 14. Schematic illustration of the laser surface melting process (Aparecida Pinto et al., 2003)

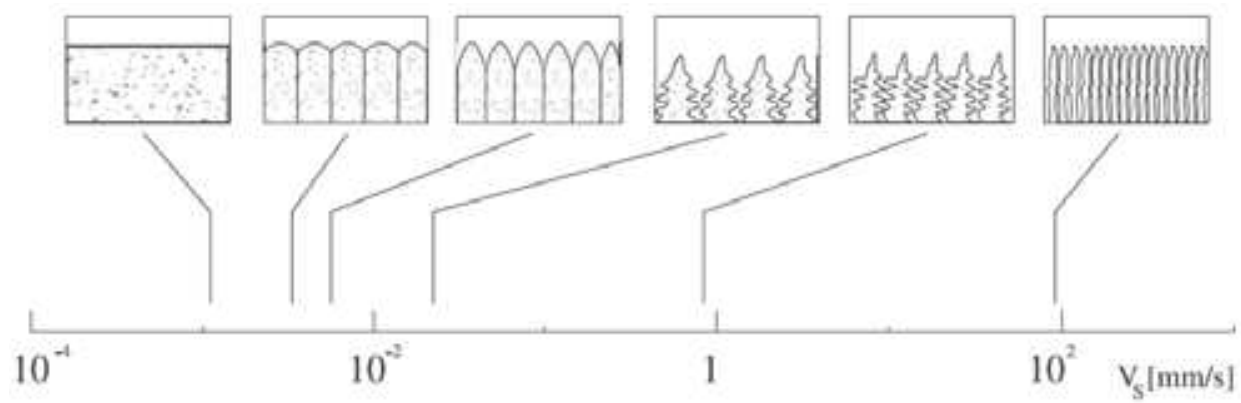

Fig. 15. Microstructure variation according to the solid/liquid front velocity (Aparecida Pinto et al., 2003)

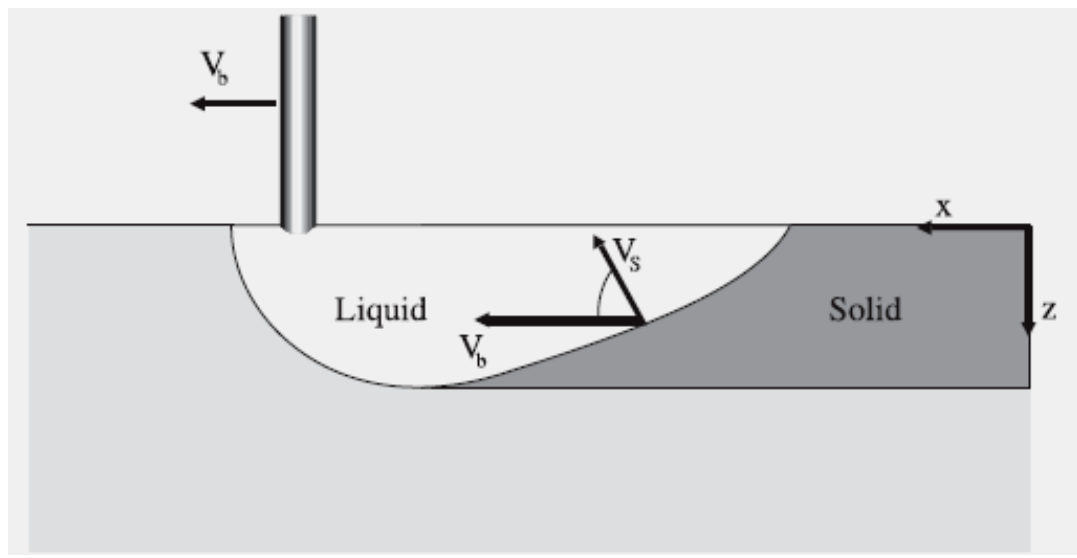

Fig. 16. Schematic representation of the relationship between solidification speed and laser beam speed (Aparecida Pinto et al., 2003) 
Taking a longitudinal section through the centerline of the laser track, the speed of the solid/liquid front $\left(V_{s}\right)$ is correlated to the beam speed $\left(V_{b}\right)$ by (Aparecida Pinto et al., 2003):

$$
\mathrm{V}_{\mathrm{s}}=\mathrm{V}_{\mathrm{b}} \cos \phi
$$

where $\phi$ is the angle between $V_{s}$ and $V_{b}$ vectors that shown in figure 16.

This equation describes that $V_{s}$ varies from zero at the bottom of the moltem pool to a approaching the value of $\mathrm{V}_{\mathrm{b}}$ at the top of the molten pool.

Pinto et. al. (Aparecida Pinto et al., 2003) investigated the microstructure of Al-Cu alloy after laser surface melting. The influence of $\mathrm{V}_{\mathrm{b}}$ on the microstructure is shown in figure 17. The lower beam speed of $500 \mathrm{~mm} / \mathrm{min}$ has permitted a more extensive cellular zone to be formed and a later transition from a cellular to a dendritic structure when compared with the structure developed under a speed of $800 \mathrm{~mm} / \mathrm{min}$.

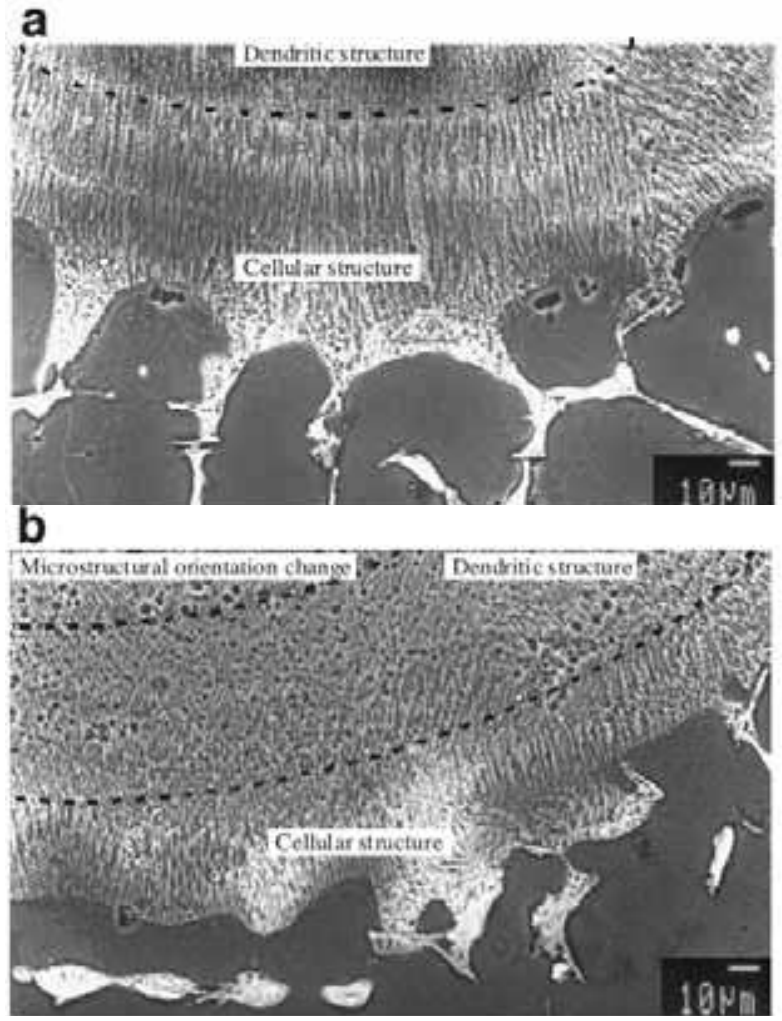

Fig. 17. Solidification morphology transitions in the molten pool. (a) $p=1 \mathrm{kw}, \mathrm{v}=500$ $\mathrm{mm} / \mathrm{min}$; (b) $\mathrm{p}=1 \mathrm{kw}, \mathrm{v}=800 \mathrm{~mm} / \mathrm{min}$ (Aparecida Pinto et al., 2003)

From the result of hardness tests, Pinto reported that the mean hardness increase from 75 $\mathrm{Hv}$ in the unmelted zone to $160 \mathrm{Hv}$ in the cellular structure. In contrast, a higher value of $210 \mathrm{Hv}$ was measured in the dendritic structure due to the fineness of the microstructure (Aparecida Pinto et al., 2003). 
Leech (Leech, 1989) studied the laser surface melting of Al-Si alloys as a function of the beam interaction time $\tau$, that determined by following equation:

$$
\tau=\frac{l}{V}
$$

Where 1 is the beam diameter and $V$ is the scanning velocity. The microstructure features in the laser-melted zone consisted of a highly refined dendritic growth at beam traverse speed of $100 \mathrm{~mm} / \mathrm{min}$. Within the structure there is a progressive change in dendrite morphology from a planar melt-substrate interface (figure 18) at the maximum melt depth, through a region of oriented columnar dendrite growth (figure 19), to a central region which at more rapid scan rates comprised a fine, filamentary eutectic (figure 20).

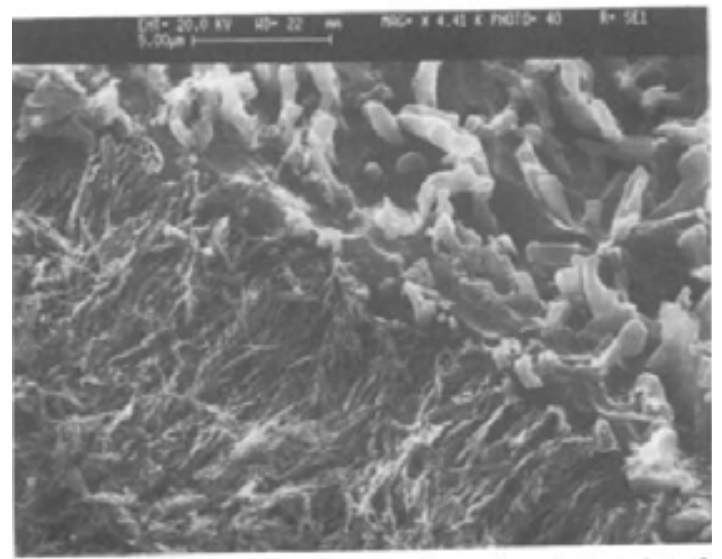

Fig. 18. SEM micrograph showing the melt-substrate interface in the Al-Si alloy (beam traverse speed, $100 \mathrm{~mm} / \mathrm{min}$ (Leech, 1989)

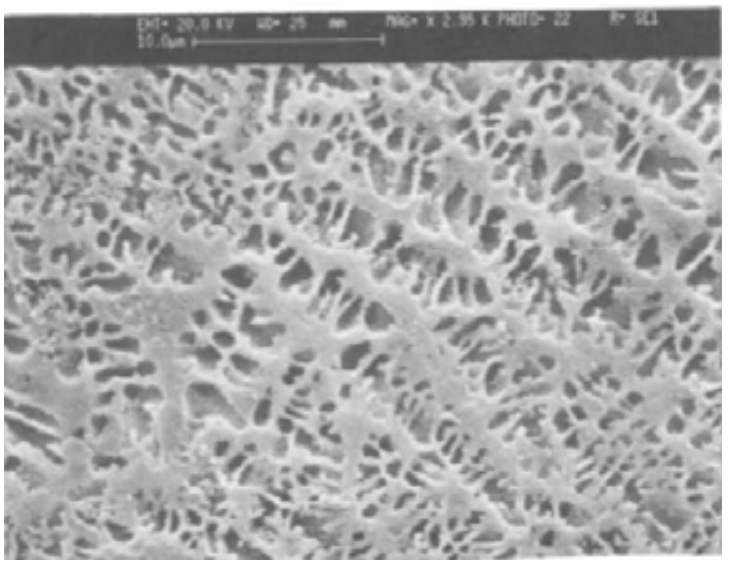

Fig. 19. SEM micrograph showing the columnar dendritic region in the melted zone in Al-SiW-Ni alloy. (traverse speed, $100 \mathrm{~mm} / \mathrm{min}$ ) (Leech, 1989) 


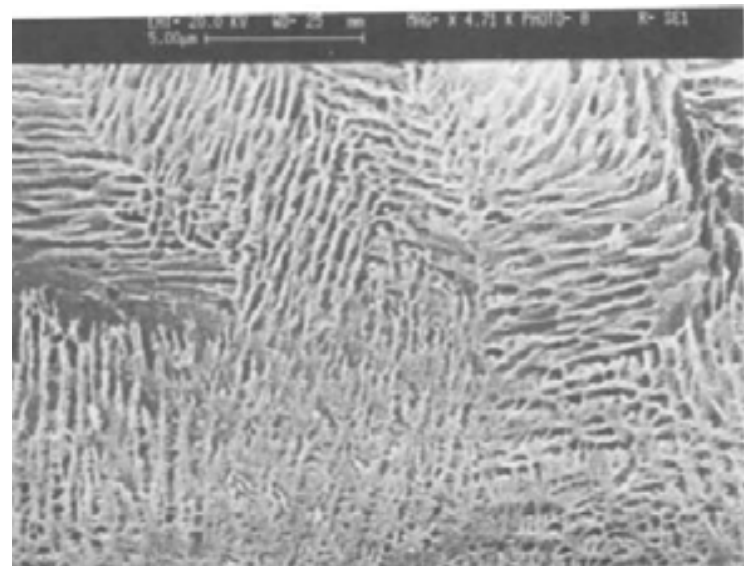

Fig. 20. SEM micrograph of the region of lamellar in Al-Si alloy at a traverse speed of 413 $\mathrm{mm} / \mathrm{min}$ (Leech, 1989)

An interpretation of the microstructures involves reference to the phase-under cooling diagram shown in figure 21. After laser melting, a rapid extraction of heat from the liquid adjacent to the substrate will produce direct cooling into the $\alpha+$ eutectic region, the resulting nucleation and growth of $\alpha$ columnar dendrites causing a rejection of silicon into the remaining melt. As the silicon content of the melt increased and with rise in temperature due to latent heat, it is proposed that the composition-cooling line moved to the right into the eutectic-coupled zone. The formation of the lamellar region in the laser melt zone thereby corresponded to the zone of couple growth (Leech, 1989).

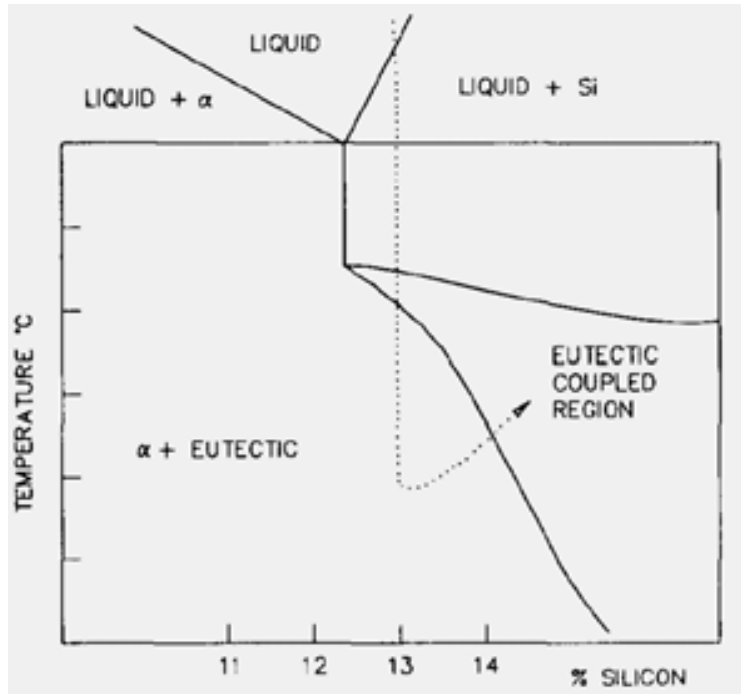

Fig. 21. Schematic phase diagram illustrating the micro structural-undercooling relations during quenching (Leech, 1989) 


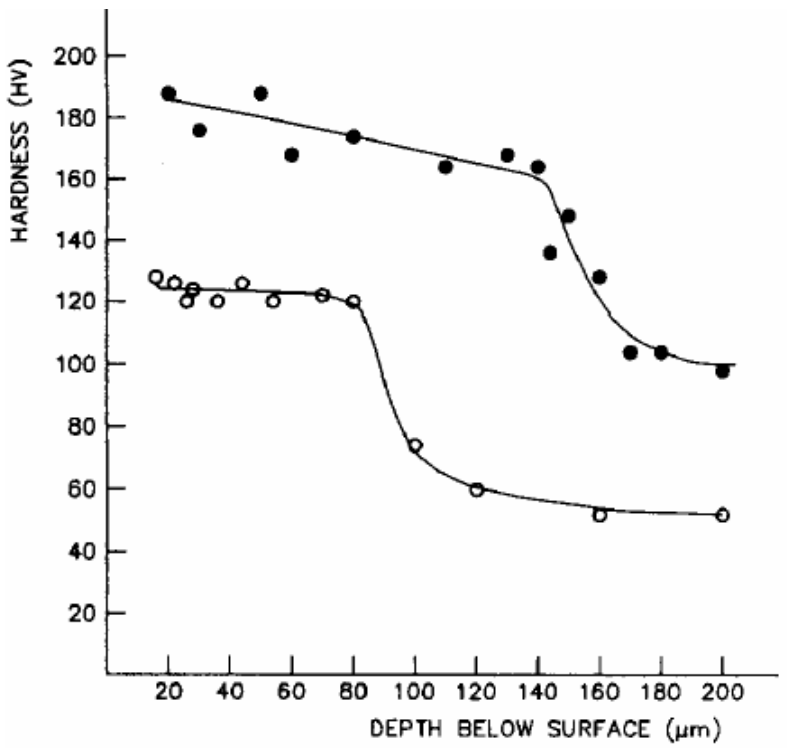

Fig. 22. Hardness profiles taken across the laser-melted regions in the Al-13.6\%Si-2.23\%Cu$1.94 \% \mathrm{Ni}(\bullet)$ and Al-13.0\% Si (०) alloys at a scan rate of $10 \mathrm{~mm} \mathrm{~s}^{-1}$ (Leech, 1989)

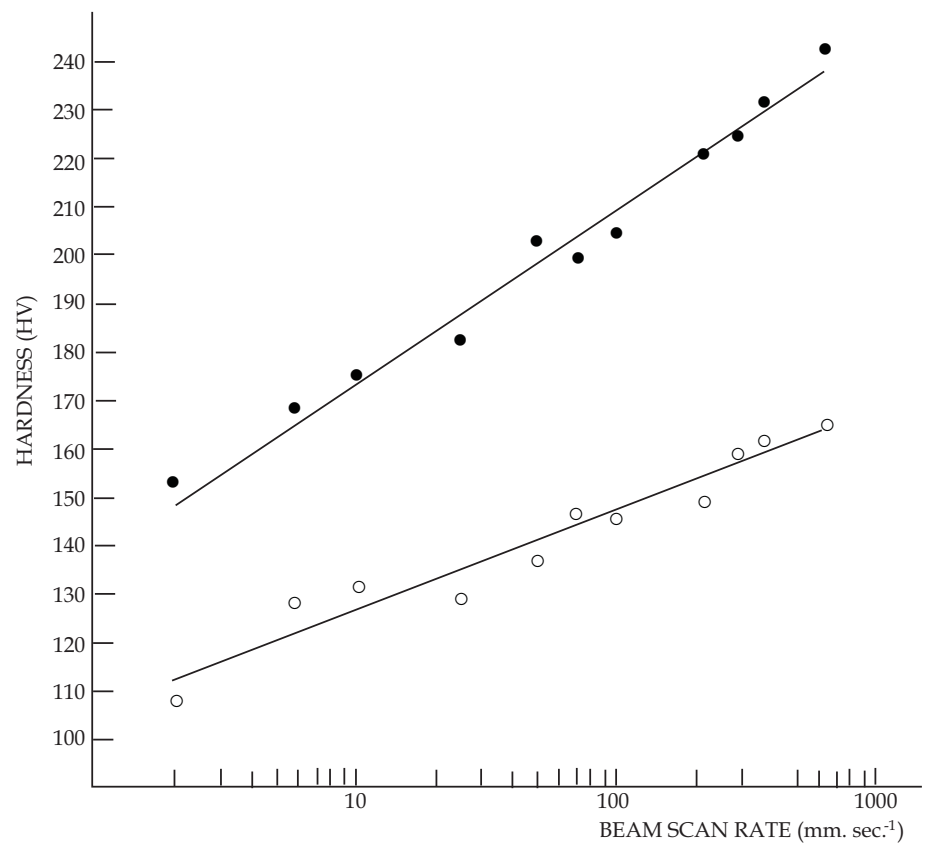

Fig. 23. Micro hardness of the melted zone in the Al-Si-Cu-Ni (•) and Al-Si (०) alloys, plotted as a function of the beam scan rate (Leech, 1989) 
The microhardness variation with distance from the melt surface after laser surface melting of Al-Si-Ni alloy and Al-Si alloy is shown in figure 22 (Leech, 1989). Apart from the differences between the alloys in molt zone depth, the curves also illustrate the higher hardness attained throughout the resolidified region of Al-Si-Cu-Ni alloy that in the Al-Si alloy. Leech (Leech, 1989) also reported that micro hardness of laser surface melted layer of $\mathrm{Al}-\mathrm{Si}-\mathrm{Cu}-\mathrm{Ni}$ and Al-Si alloys is dependent on laser scan rate (figure 23).

Increasing quenching rates, may promote the formation of finer dispersions of copper and nickel-bearing intermetallic particles (Leech, 1989).

Corrosion resistance is an important matter in aluminum alloys. There are several methods of surface engineering to improving the corrosion behavior of aluminum alloys, that everyone has advantages and disadvantages. Laser surface melting is one of those techniques. There have been a number of studies of the influence of LSM on the corrosion properties of aluminum alloys, and the results achieved have been ambiguous with respect to the benefits of LSM. In some cases, it is severally accepted that laser surface melting can be used for improving the localized corrosion resistance of aluminum alloys as a result of homogenization and refinement of microstructures, and phase transformations. For example, Chong et. al (Chong et al., 2003) studied the corrosion behavior of Al-2014 alloy in T6 and T451 conditions after laser surface melting. After the corrosion tests, they found a large number of pits, randomly distributed on the surface of as-received Al2014 alloy in two conditions (figure 24a). In this instances although Al2014 alloy in both tempers consisted of similar types of intermetallic particles, the copper content in the aluminum matrix for $\mathrm{T} 6$ is lower than that for T451. In the $\mathrm{NaCl}$ electrolyte, $\mathrm{Al}_{2} \mathrm{Cu}$, and $\mathrm{Al}-\mathrm{Cu}-\mathrm{Mn}-\mathrm{Fe}-\mathrm{Si}$ particles tend to be cathodic to the matrix (Chong et al., 2003), and pits are likely to initiate and grow in the copper-depleted zone around these particles (Guillaumin \& Mankowski, 1999). $\mathrm{Mg}_{2} \mathrm{Si}$ particles are anodic to the aluminum matrix, and have a tendency to dissolve and leaving cavities. Figure $24 \mathrm{~b}$ shows that after LSM, pits formed on the laser-melted surfaces are larger but shallower that in the as- received alloy, with a semi-continuous network, consisting of copper-rich precipitates, remaining within the pits, indicating their cathodic nature. It is proposed that the concentrations of solid solution alloy elements, (particularly copper in $\mathrm{Al}$ 2014), are key factors influencing pitting corrosion. Such increase of copper content in the $\mathrm{Al}$ 2014 matrix can reduce the potential difference between the $\mathrm{Al}_{2} \mathrm{Cu}$ phases and the aluminum matrix, thereby reducing the driving force of pitting corrosion. The reduction in population or the elimination of $\mathrm{Mg}_{2} \mathrm{Si}$ particles which are anodic to aluminum matrix may

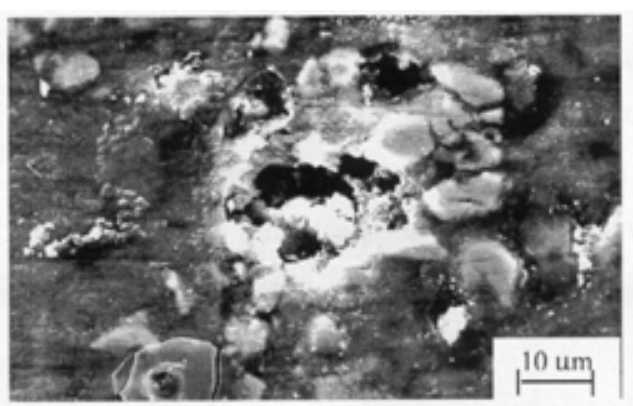

(a)

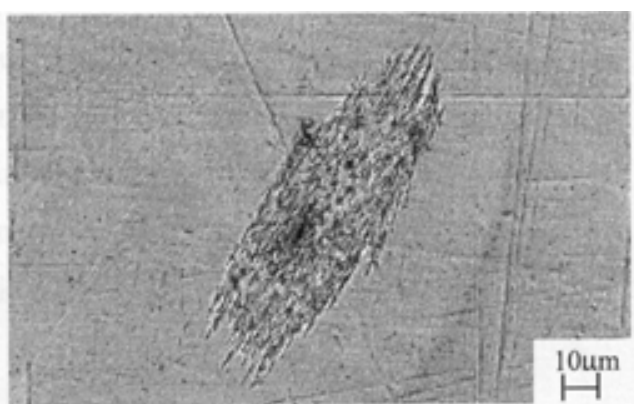

(b)

Fig. 24. Pit morphology of (a) as- received Al 2014- T6 alloy and (b) laser- melted Al 2014T6 alloy (Chong et al., 2003) 

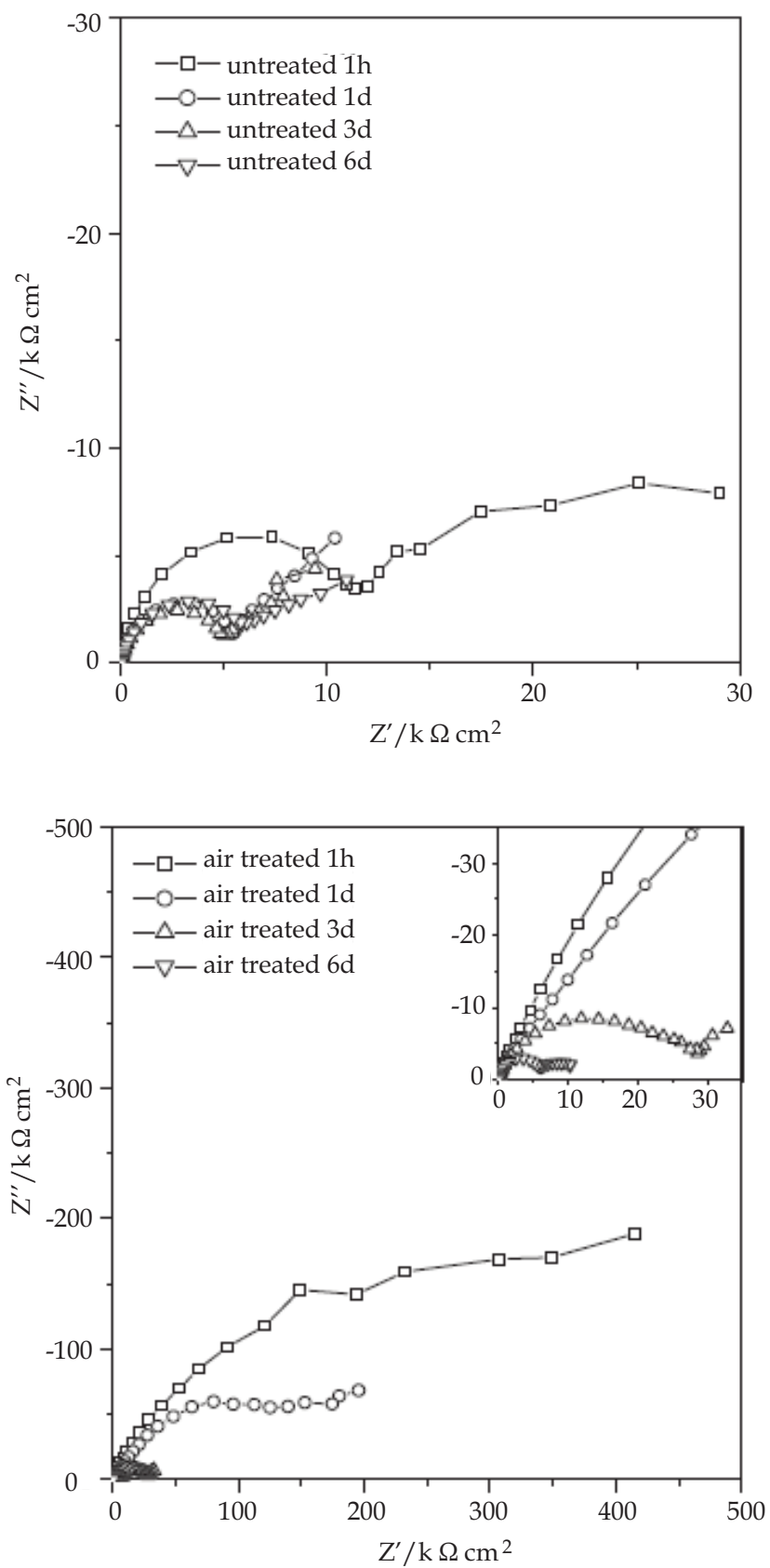

Fig. 25. Nyquist plots of the (a) untreated specimen, (b) laser, treated Al-6013 alloy (Xu et al., 2006) 
further improve the behavior by reducing cavities due to the dissolved particles. Regarding influences of preferred orientation, the literature (Guillaumin \& Mankowski, 1999) indicates that the pitting potential of aluminum increases in order of $\left(\mathrm{E}_{\mathrm{pit}}\right)_{\{001\}} \geq\left(\mathrm{E}_{\mathrm{pit}}\right)_{\{011\}}>\left(\mathrm{E}_{\mathrm{pit}}\right)_{\{111\}}$, however, the presence of alloyed copper in solid solution reduces the dependence of $\mathrm{E}_{\text {pit }}$ on surface orientation. Thus, the preferred orientation of $\alpha$-Al along [200] direction in lasermelted alloy does not appear to play a significant role in the improved pitting behavior.

High- strength aluminum alloys (HSAL) are high susceptible to various forms of corrosion, particularly in the presence of chloride-containing media. Thus, these alloys are very susceptible to pitting corrosion fatigue, and the degradation of HSAL by this phenomenon is a matter of major concern, particularly as many structural parts are inaccessible for inspection and cannot be monitored, thus hiding the defects of corrosion as they approach a critical for fatigue. The improvement in pitting corrosion fatigue behavior of HSAL alloys after LSM is reported by $\mathrm{Xu}$ and co-workers (Xu et al., 2006). Figure 25 shows the results of impedance measurements of unmelted and surface melted $\mathrm{Al} 6013$ alloy. These results are displayed in the form of Nyquist plots as a function of immersion time up to a period of 6 days.

The spectra suggest that for untreated and laser-treated Al alloy, corrosion pitting has occurred to various degrees at different times during the immersion test. This is evidenced by the presence of start of the immersion test, with the diameter of the arches decreasing with immersion time (figure 25a).

As for the laser- treated $\mathrm{Al} 6013$ alloy, a compressed capacitive loop with a small diffusion tail at the low-frequency range was seen at the first hour of the test, and a second loop emerged after 1 day of immersion (figure 25b). Figure 26 shows the equivalent circuit of EIS plots to interpret the electrochemical behavior of untreated and laser-treated $\mathrm{Al} 6013$ alloy. The equivalent circuit component values as a function of immersion time are listed in table 1.

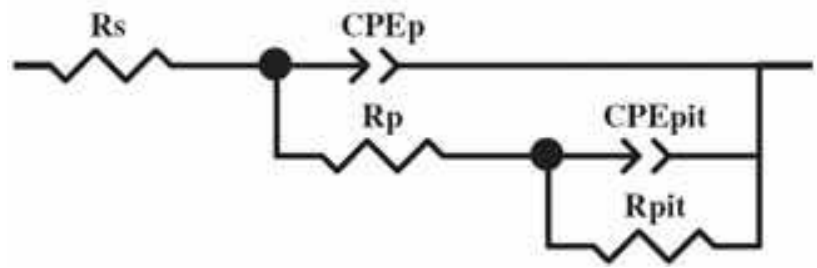

Fig. 26. Equivalent circuits for the untreated and laser-treated Al 6013 alloy (Xu et al., 2006)

\begin{tabular}{|c|c|c|c|c|c|c|c|}
\hline \multirow[t]{2}{*}{ Specimen } & & \multicolumn{2}{|l|}{$\mathrm{CPE}_{\mathrm{p}}$} & \multirow[t]{2}{*}{$\underline{R_{\mathrm{p}}, \Omega \mathrm{cm}^{2}}$} & \multicolumn{2}{|l|}{$\mathrm{CPE}_{\text {pit }}$} & \multirow[t]{2}{*}{$R_{\text {pit }}, \Omega \mathrm{cm}^{2}$} \\
\hline & & $Y_{0}, \mathrm{~F} \mathrm{~cm}^{-2} \mathrm{~Hz}^{1-n}$ & $n$ & & $Y_{0}, \mathrm{~F} \mathrm{~cm}^{-2} \mathrm{~Hz}^{1-n}$ & $n$ & \\
\hline \multirow[t]{4}{*}{ Untreated } & $1 \mathrm{~h}$ & $5.74 e-6$ & 0.93 & $1.28 \mathrm{e} 4$ & $2.26 e-4$ & 0.94 & $1.85 \mathrm{e} 4$ \\
\hline & 1 day & $1.23 e-5$ & 0.91 & $5.99 \mathrm{e} 3$ & $6.87 e-4$ & 0.85 & $1.53 \mathrm{e} 4$ \\
\hline & 3 days & $1.71 \mathrm{e}-5$ & 0.89 & $5.50 \mathrm{e} 3$ & $9.81 \mathrm{e}-4$ & 0.90 & $7.00 \mathrm{e} 3$ \\
\hline & 6 days & $2.04 \mathrm{e}-5$ & 0.88 & $6.68 \mathrm{e} 3$ & $7.77 e-4$ & 0.84 & $8.47 \mathrm{e} 3$ \\
\hline \multirow[t]{4}{*}{ Air-treated } & $1 \mathrm{~h}$ & $4.52 \mathrm{e}-6$ & 0.62 & $6.54 \mathrm{e} 5$ & & & \\
\hline & 1 day & $1.69 \mathrm{e}-6$ & 0.83 & $1.29 \mathrm{e} 4$ & $4.12 e-6$ & 0.65 & $1.873 \mathrm{e} 5$ \\
\hline & 3 days & $4.80 e-6$ & 0.74 & $2.67 \mathrm{e} 4$ & $4.64 \mathrm{e}-4$ & 0.53 & 3.3104 \\
\hline & 6 days & $1.84 e-5$ & 0.91 & $6.70 \mathrm{e} 3$ & $8.58 \mathrm{e}-4$ & 0.94 & $4.65 \mathrm{e} 3$ \\
\hline
\end{tabular}

Table 1. Calculated values of the equivalent circuit components of the impedance plots $(\mathrm{Xu}$ et al., 2006) 
The magnitude $\mathrm{CPE}_{\mathrm{p}}$ (constant phase element), a measure of the capacitance at the surface of laser- melted alloy is much less than that of the as-received alloy, especially up to the immersion time of 3 days. This indicates that less ion adsorption has occurred at the surface of the laser melted alloy. This confirms the good corrosion resistance of the layers containing laser-formed aluminum oxide in reducing the rate of electro chemical reaction at the lasermeted surface. Xu (Xu et al., 2006) reported that the corrosion fatigue life of the laser-surface melted $\mathrm{Al} 6013$ alloy is two times longer than that of the as-received $\mathrm{Al}$ alloy (figure 27). Also, the corrosion current for the laser-surface melted Al 6013 alloy is considerably lower than that for the as-received $\mathrm{Al} 6013$ alloy. The improvement in the pitting corrosion of the laser-surface- melted $\mathrm{Al}$ alloy. An increase in the corrosion resistance of $\mathrm{Al}-\mathrm{Si}$ alloys after laser surface melting in both $10 \% \mathrm{H}_{2} \mathrm{SO}_{4}$ and $10 \% \mathrm{HNO}_{3}$ solutions is observed by Wong and co-workers (Wong \& Liang, 1997). Also, they reported that, in the $10 \% \mathrm{HCl}$ and $5 \% \mathrm{NaCl}$ solutions laser melting has little effect on the corrosion resistance of Al-Si alloys. Because the $\mathrm{Cl}$ ions destroy the $\mathrm{Al}_{2} \mathrm{O}_{3}$ film completely. In the case of $5 \% \mathrm{NaCl}$ solution, $\mathrm{NaAlO}_{2}$ is formed and the protective oxide film $\mathrm{Al}_{2} \mathrm{O}_{3}$ is again destroyed, which intensifies the corrosion of the aluminum alloys (Yongqing et al., 1998).

Corrosion resistance of laser surface melted Al 2024 alloy is investigated by $\mathrm{Li}$ and coworkers ( $\mathrm{Li}$ et al., 1996). Free corrosion in naturally aerated chloride electrolyte solution revealed a change in the mechanism of corrosion for the LSM alloy. A small number of large pits, initiated in the $\alpha-\mathrm{Al}$ cells and/or dendrites, are found at random over the surface. In contrast, for the as-received alloy where pitting is initiated at $\mathrm{Al}_{2} \mathrm{CuMg}$ precipitates, corrosion took the form of intergranular corrosion.

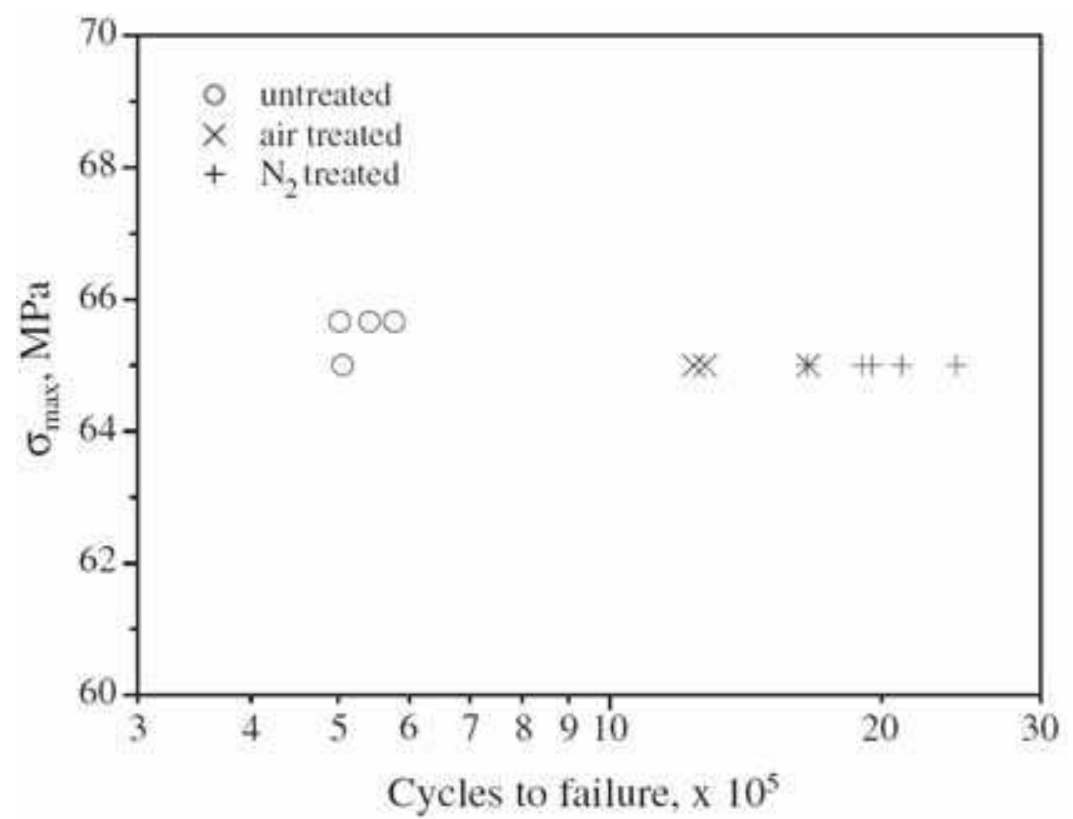

Fig. 27. Test of the fatigue life of the untreated and laser- treated $\mathrm{Al} 6013$ alloy in a $3.5 \% \mathrm{NaCl}$ solution at a potential of $-675 \mathrm{mv}$ (Xu et al., 2006) 


\section{Laser surface cladding of aluminium alloys}

Aluminium-based metal matrix composites (Al-MMC $\mathrm{S}_{\mathrm{s}}$ ) have high strength, hardness and wear resistance, and find application in various industrial sectors, such as automotive and aerospace industries (Anandkumar et al,. 2007). The major drawbacks of these materials are their high coat and complex production methods compared to conventional alloys, but for many applications, like rapid tooling, the bulk stress levels are compatible with the use of high-strength $\mathrm{Al}$ alloy, the required wear resistance being achieved by coating the component with a high wear resistance materials such as a ceramic-reinforced Al-matrix composite (Anandkumar et al,. 2007). Aluminium alloys have been cladded with ceramics such as $\mathrm{SiC}, \mathrm{B}_{4} \mathrm{C}, \mathrm{TiC}$ due to their high hardness and thermal stability and various other metallic materials such as $\mathrm{Ti}, \mathrm{B}, \mathrm{Ni}$ etc. to enhance their surface properties (Anandkumar et al,. 2007). These ceramic reinforcement particles have a low reflectivity; therefore they absorb a considerable amount of laser energy (Anandkumar et al., 2009) and may reach very high temperatures, which will lead to intense reactions between the reinforcement and the liquid metal or to particle dissolution in the melt pool. The tendency of reactivity of reinforcement particles with depends on their temperature, which depends on the interaction time between the particles and the laser beam (Anandkumar et al., 2009).

In this case, the velocity of injected powder is an important factor that affects on the interaction time and particles temperature. The temperature variation of injected powder particles is calculated by several researchers using mathematical modeling. Huang et al. (Huang et al., 2005) calculated the beam attenuation and particle temperature variation due to the interaction of an off-axis powder stream with a laser beam on the basis of LambertBeer law and Mie's theory. They found that the temperature of injected powder particles increases with decreasing the angle between the powder jet and the laser beam from 45 to $0^{\circ}$, because the particles trajectory through the laser beam is longer.

Also, a mathematical model for calculation of particles temperature under laser beam irradiation is established by jouvard and co-workers (Jouvard et al., 1997). Figure 28 shows an off-axis blown powder laser cladding process diagram used for jouvard model.

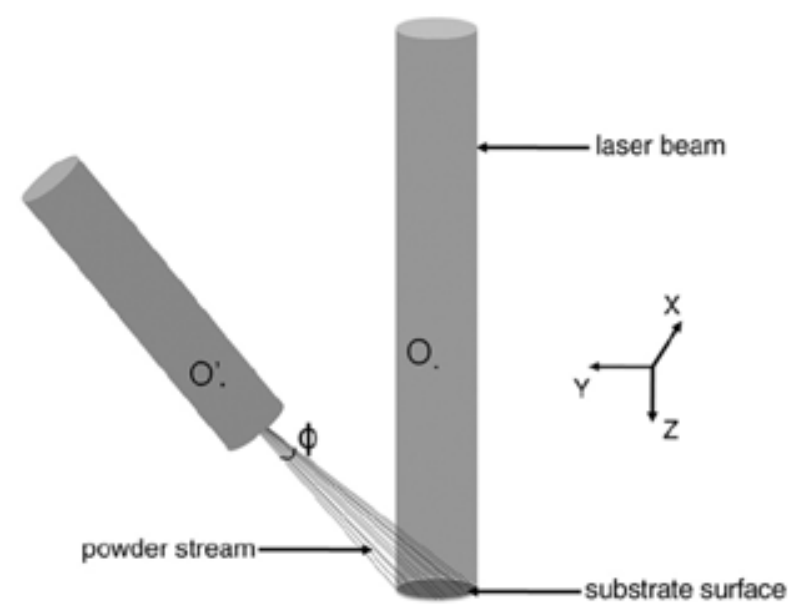

Fig. 28. Diagram of laser beam-powder stream interaction (Anandkumar et al., 2009) 
They reported that, the temperature of a powder particle $(\mathrm{T})$ interacting with the laser beam can be calculated by (Jouvard et al., 1997):

$$
T=T_{0}+\frac{I_{(x, y)} \eta A_{p} t}{m_{p} c_{p}}
$$

Where

$\mathrm{T}_{0}$ initial temperature of the particles $\left(25^{\circ} \mathrm{C}\right)$

$\mathrm{I}_{(\mathrm{x}, \mathrm{y})}$ laser radiation intensity

$\eta$ absorptivity of the particle material

$\mathrm{A}_{\mathrm{p}}$ cross-sectional area of the particle

$\mathrm{m}_{\mathrm{p}}$ mass of the particle

$c_{p}$ specific heat capacity of the particle material

$t$ laser beam-particle interaction time

In this equation following simpler assumptions is considered:

1. the laser beam is parallel and has a Gaussian energy distribution.

2. the powder particles are spherical and uniformly distributed in the powder stream,

3. energy loss by convection and radiation is negligible (Fu et al., 2002),

4. the effect of gravity and the drag exerted by the surrounding gas on particle movement are negligible and all particles have the same velocity,

5. the shadow effect of the particles on each other is accounted for,

6. the fraction of the laser beam energy absorbed by a particle is given by the absorptivity of the particle material ( $\eta$ ) for the laser radiation wavelength,

7. the temperature distribution in each particle is uniform,

8. latent heat effects due to melting are neglected (Anandkumar et al., 2009).

As the interaction time $(t)$ is given by $d / v_{p}$, where $d$ is the distance traveled by the particle through the laser beam and $v_{p}$ its projected velocity component, Eq. (7) can be written as:

$$
T=T_{0}+\frac{I_{(x, y)} \eta A_{p} d}{m_{p} c_{p} v_{p}} .
$$

The trajectories of the particles are represented by a series of lines diverging from $\mathrm{O}$ (Figure 28) and the energy absorbed by particle is calculated as a line trajectory integral through laser beam, because the intensity of the beam depends on $\mathrm{x}$ and $\mathrm{y}$ and finally also on $\mathrm{z}$. To establish a function describing the laser beam attenuation in the $\mathrm{z}$ direction, the interaction region is divided into $\mathrm{n}$ layers of thickness $\Delta \mathrm{z}$ and the fraction of radiation intensity (C) absorbed by the particles in each layer is calculated using the following equation:

$$
C=I_{(x, y)} \eta A_{p} \Delta z\left(\frac{N}{V}\right)
$$

where $(\mathrm{N} / \mathrm{V})$ is the density of the powder stream, which depends on the powder feed rate and the injection velocity (Gingu et al., 1999). The particles in the n-th layer absorb part of the incoming radiation intensity and the remaining intensity is regarded as the input intensity for the $n+1$ layer and so on. The final temperature of the particles is computed by solving Eq. (10) using Wolfram Research Mathematica ${ }^{\circledR} 6$ software, 


$$
T=T_{0}+\frac{\eta A_{p}}{v_{p} m_{p} c_{p}} \int_{z_{s}}^{z_{o}}\left(I_{(x, y)}-C\right)^{(n-1)} d d z
$$

where, the integral limits $z_{s}$ and $z_{o}$ are the $z$ coordinates of the pointwhere the particle enters the beam and impinges the substrate, respectively (Anandkumar et al., 2009).

In case of modification using many ceramics, especially carbides, it has been found that they also chemically react with $\mathrm{Al}$ and form compounds which decrease the strength of Aluminum alloy. For example, ceramic particles of $\mathrm{SiC}$, tend to react and dissolve in molten $\mathrm{Al}$ alloy, and leading to the formation of $\mathrm{Al}_{4} \mathrm{C}_{3}$ and ternary $\mathrm{Al}-\mathrm{Si}-\mathrm{C}$ carbides during solidification (Viala et al., 1990; Hu et al., 1996) according to the reaction at a temperature range between 940 and $1620 \mathrm{k}$ (Anandkumar et al., 2007):

$$
4 \mathrm{Al}_{(\mathrm{l})}+3 \mathrm{SiC}_{(\mathrm{s})} \rightarrow \mathrm{Al}_{4} \mathrm{C}_{3(\mathrm{~s})}+3 \mathrm{Si}
$$

At higher temperatures (above $1670 \mathrm{k}$ ), the reaction product is the ternary carbide $\mathrm{Al}_{4} \mathrm{SiC}_{4}$, formed by the reaction (Anandkumar et al., 2007):

$$
4 \mathrm{Al}_{(\mathrm{l})}+4 \mathrm{SiC}_{(\mathrm{s})} \rightarrow \mathrm{Al}_{4} \mathrm{SiC}_{4(\mathrm{~s})}+3 \mathrm{Si}
$$

The presense of this phase in microstructure of $\mathrm{Al}$ alloy is shown in figure 29a (Anandkumar et al., 2009). The hardness of $\mathrm{Al}_{4} \mathrm{C}_{3}$ is very lower then $\mathrm{Al}_{4} \mathrm{SiC}_{3}$ (300 and 1200 $\mathrm{Hv}$, respectively) but, unlike $\mathrm{Al}_{4} \mathrm{SiC}_{4}$, it is brittle and tends to react with water, forming aluminium hydroxide (Anandkumar et al., 2007).

Accordingly, the presence of $\mathrm{Al}_{4} \mathrm{C}_{3}$ in the surface microstructure results in poor mechanical properties and low long-term stability (Anandkumar et al., 2007) and its formation must be avoided.

According to the equation 10, Anandkumar et al. (Anandkumar et al., 2009) calculated the $\mathrm{SiC}$ particle temperature at two different jet velocities for laser surface cladding of Al-Si alloy. They found that when the particle injection velocity is $5 \mathrm{~m} / \mathrm{s}$, the particles are exposed to the laser radiation for a shorter time and they absorb correspondingly less energy. As a result, the temperature of the particles reaching the melt pool is much lower and no significant reactions occur between $\mathrm{SiC}$ and molten aluminum, leaving the composition of the melt essentially unchanged. During cooling this liquid solidifies as primary $\alpha-\mathrm{Al}$ dendrites and $\alpha-\mathrm{Al}+\mathrm{Si}$ eutectic (Figure $29 \mathrm{~b}$ ).
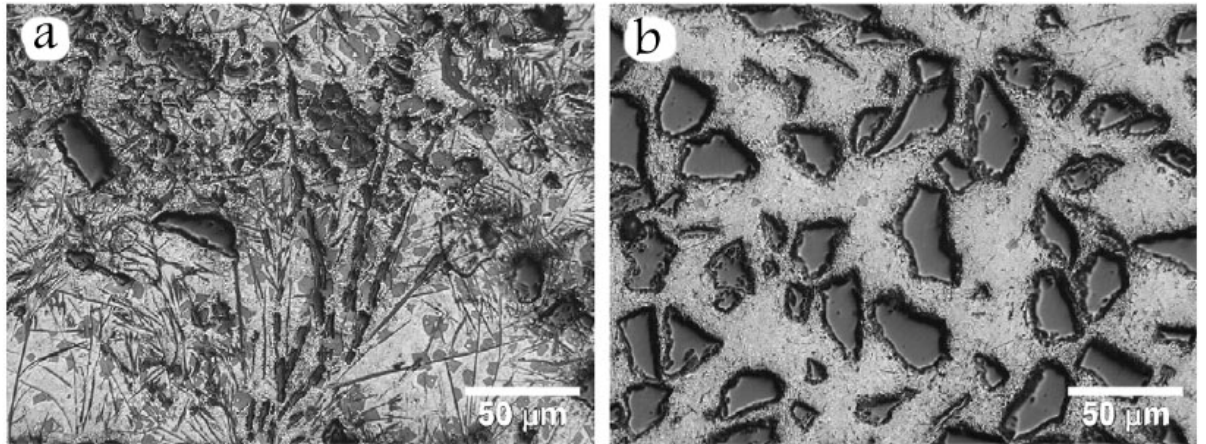

Fig. 29. Microstructure of clad tracks prepared at particle injection velocities of (C) $1 \mathrm{~m} / \mathrm{s}$ and (d) $5 \mathrm{~m} / \mathrm{s}$ (Anandkumar et al., 2009) 
Due to the lower absorption of laser beam energy by aluminum alloy, the temperature of metallic particles is always much lower than that of ceramic particles. The maximum temperature attained by the particles as a function of their injection velocity is shown in figure 30 (Anandkumar et al., 2009). Also, the temperature distribution of SiC particles injected at $1 \mathrm{~m} / \mathrm{s}$ along the $X$ axis $(y=0)$ is shown in figure 31. Particles arriving at the $X$ axis traveled the same time through the laser beam: particles reaching the surface near the laser beam axis are subjected to higher radiation intensity and reach higher temperatures, while the temperature decreases towards the periphery of the powder stream as the beam intensity decreases. By contrast, the temperature of the particles increases linearly along the $\mathrm{Y}$ axis (Figure 32). Two factors explain this evolution. On one hand, the length of the particle's path through the laser beam varies along the line: it is zero for particles reaching the leading edge of the melt pool and increases with $Y$ up to the trailing edge of the melt pool, where it reaches its maximum value. On the other hand, attenuation of the laser beam by the particles, which decreases from the leading to the trailing edge, further enhances the particle's temperature increase in this direction. The present results show that particle injection velocity is a key parameter in control of the microstructure and properties of metal matrix composite coatings produced from metal-ceramic powder mixtures by laser cladding and laser particle injection (Anandkumar et al., 2009). The particles injection velocity must be kept higher than a certain threshold to avoid excessive heating of the ceramic particles reaching the melt pool and potential reactions between the reinforcement material and the liquid metal.

Other laser parameters such as the power of laser and scanning rate have an important effect on the properties and features of clad layers. Sallamand and Pelletier (Sallamand \& Pelletier, 1993), (during laser cladding of aluminium-base alloy with Al-Si and Ni-Al powders), found that at low laser powers or high scanning speeds (or both), some of the injected particle are unmelted and some porosity is sometimes detected as shown in figure 33. Also, with higher power or lower scanning.

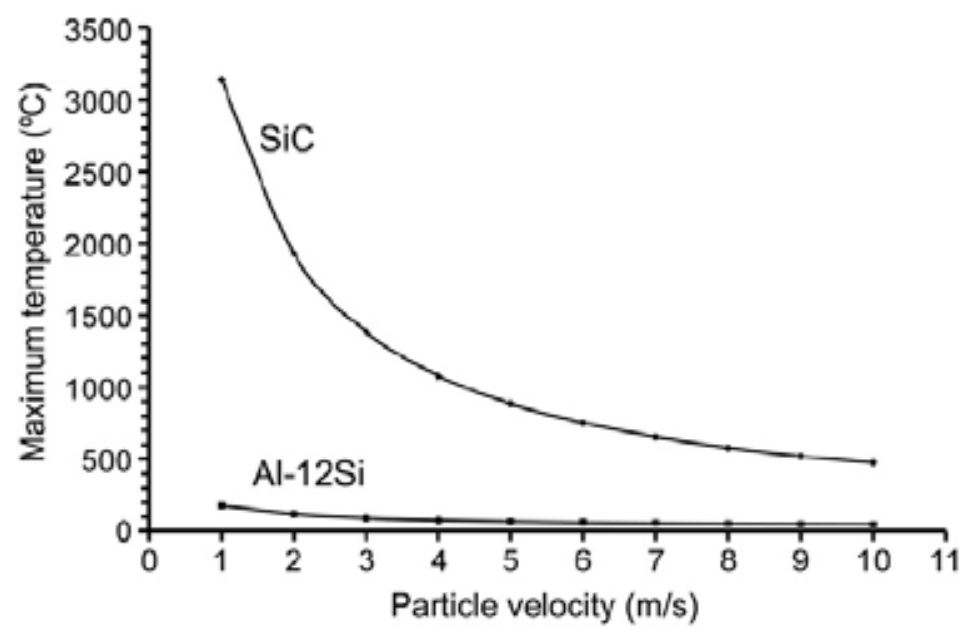

Fig. 30. Maximum temperature attained by the particles as a function of their injection velocity (Anandkumar et al., 2007) 


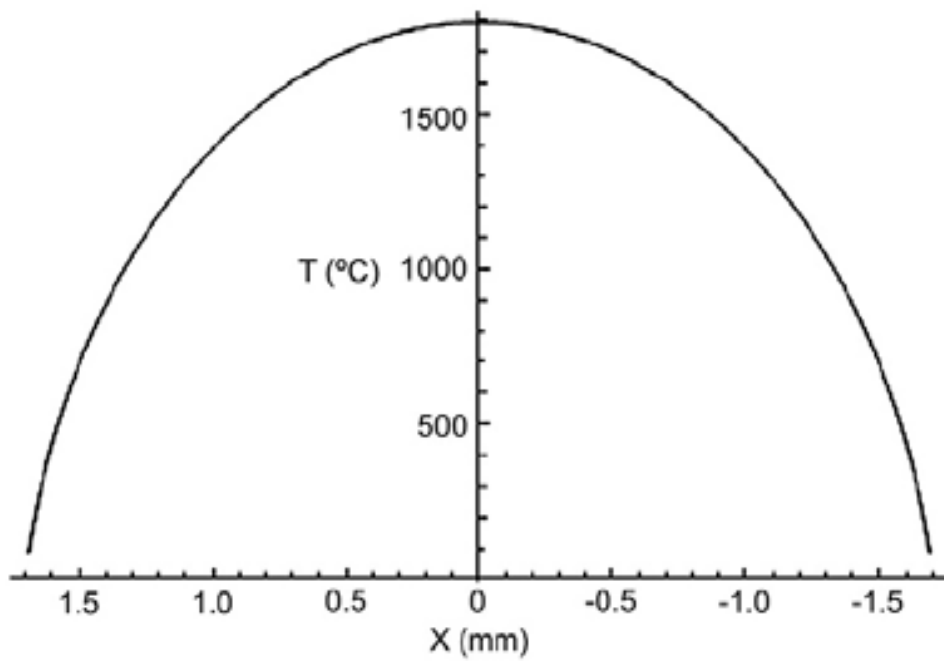

Fig. 31. Temperature distribution of $\mathrm{SiC}$ particles injected at $1 \mathrm{~m} / \mathrm{s}$ along the $\mathrm{X}$ axis $(\mathrm{y}=0)$ (Anandkumar et al., 2007)

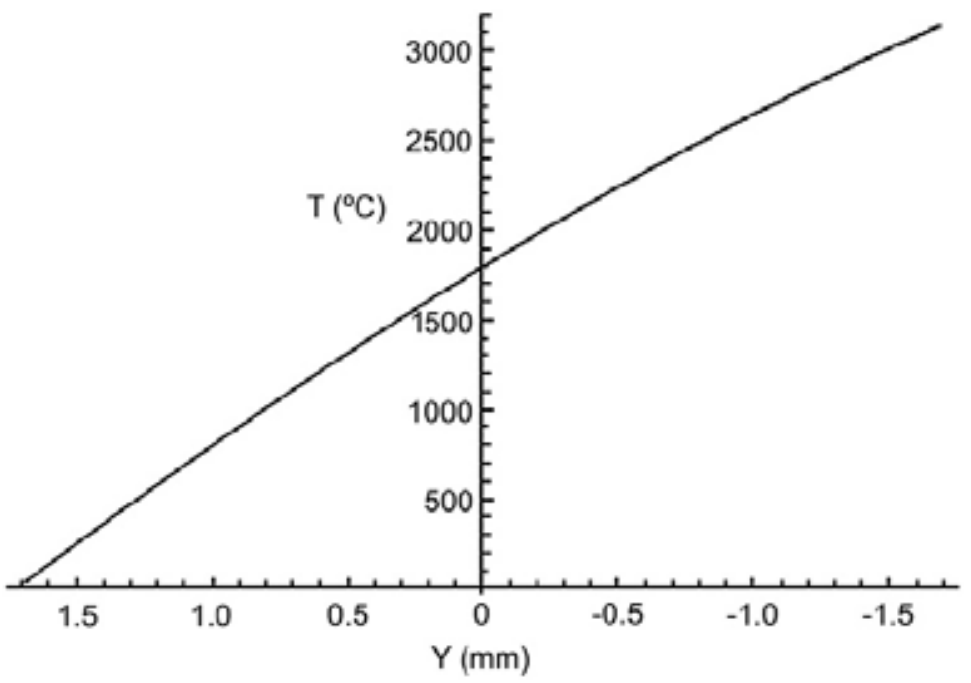

Fig. 32. Temperature distribution of $\mathrm{SiC}$ particles injected at $1 \mathrm{~m} / \mathrm{s}$ along the $\mathrm{Y}$ axis $(\mathrm{x}=0)$ (Anandkumar et al., 2007)

Speeds, or both, i. e. with a higher interaction time $\tau$ and/or a higher absorbed energy, melting of the injected particles occur, as mentioned above. When the power fraction absorbed by the powder is higher than that by the substrate, only limited melting of the substrate occurs and therefore cladding is formed, with a low dilution rate of the incoming powder. 


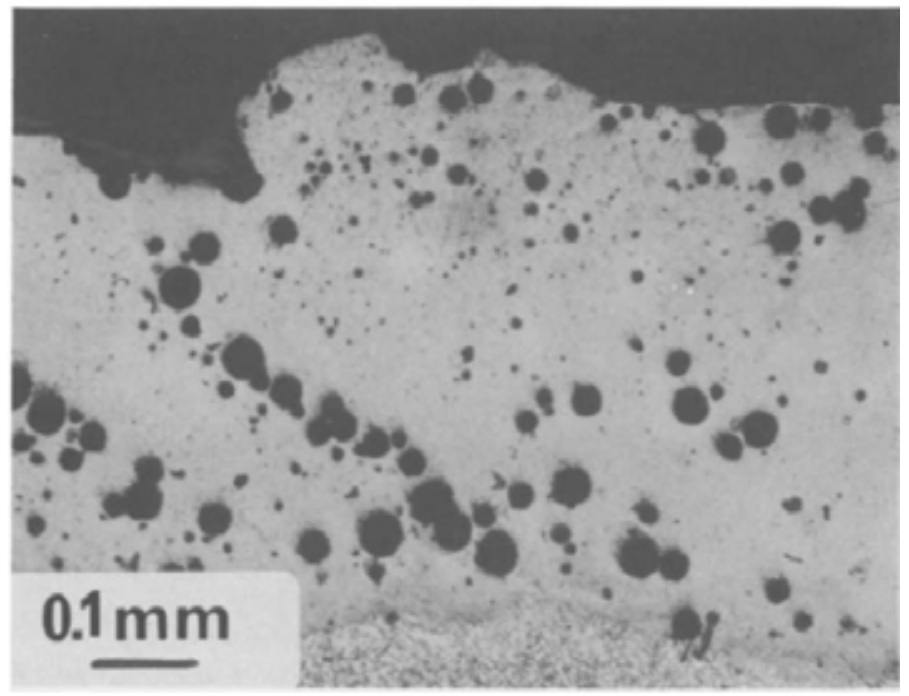

Fig. 33. Micrograph of cladding before optimization of the processing conditions showing that pores are detected. (AI-7at. \% Si+injection of (AI, Si,Ni) powders; laser power $\mathrm{P}=1900$ $\mathrm{W}$; scanning speed $\mathrm{v}=1.5 \mathrm{~cm} \mathrm{~s}^{-1}$; diameter $\mathrm{d}$ of the laser beam on the sample $1.25 \mathrm{~mm}$; magnification $G=100$ ) (Sallamand \& Pelletier, 1993)

About the Ni powder, when adding the Ni powder into the melted aluminum alloy zone, it is the need for good homogenization of the nickel. The diffusion-controlled process can be enhanced by increasing the temperature, but then vaporization and plasma formation above the sample have to be avoided in order to obtain regular treated zones. It can also be enhanced by increasing the interaction time; however, an increase in the lifetime of the melted pool yields an increase in the melted depth and, consequently, a higher dilution rate of the nickel (Sallamand \& Pelletier, 1993). The microstructure of a typical cladding is shown in Figure 34. It appears to be mainly dendritic. The orientations of the dendrites are not very regular; two explanations can be proposed:

1. A cross-section effect of a three-dimensional network occurs, where dendrites are perpendicular to the solidification front which progresses from the bottom to the top of the sample.

2. Convection movements in the melted pool can modify the regularity of the growth direction, since they induce perturbations, both in the thermal gradients and in the chemical composition (Sallamand \& Pelletier, 1993). Nevertheless, the main result is the existence of a fine and dendritic microstructre, without cracks, pores or undissolved nickel, aluminium or silicon particles. Therefore the duration of the melted pool was long enough to achieve first complete melting of the injected particles and then good interdiffusion of the different elements. It may be observed in Figure 35 that the geometrical features of the dendrites are progressively modified from the interfacial zone to the surface of the sample; a progressive refinement occurs. This phenomenon is due to the evolution of the solidification rate during the process itself: as shown by many workers this rate starts from zero at the interface and increases to a maximum value at the end of the phenomenon, on the surface of the specimen. 


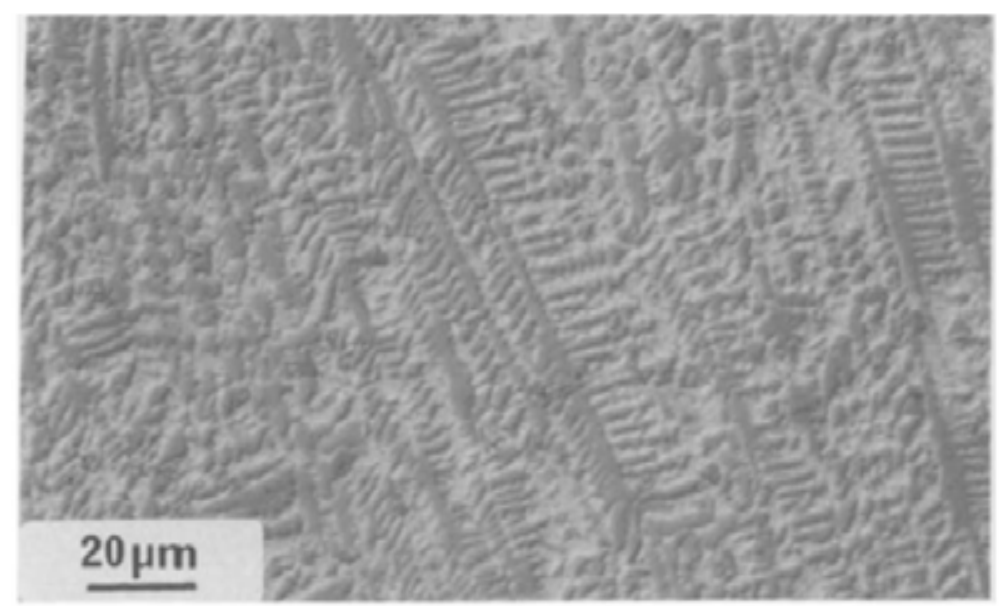

Fig. 34. Microstructure of typical cladding (AI-7at.\%Si + injection of (AI, Si, Ni) powders; laser powcr $\mathrm{P}=2800 \mathrm{~W}$; scanning speed $\mathrm{t},=1.5 \mathrm{~cm} \mathrm{~s}^{-1}$; diameter $\mathrm{d}$ of the laser beam on the sample, $1.25 \mathrm{~mm}$; magnification $\mathrm{G}=80$ ) (Sallamand \& Pelletier, 1993)

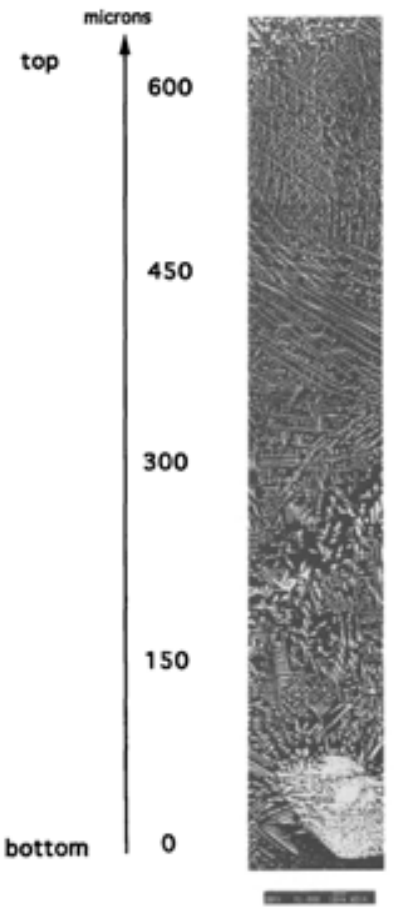

Fig. 35. Evolution of the size of the dendrites from the bottom to the top of the cladding (AI7at.\%Si+injection of $(\mathrm{AI}, \mathrm{Si}, \mathrm{Ni})$ powders; laser power $\mathrm{P}=2800 \mathrm{~W}$; scanning speed $\mathrm{v}=2.0 \mathrm{~cm}$ $\mathrm{s}^{-1}$; diameter $\mathrm{d}$ of the laser beam on the sample, $1.25 \mathrm{~mm}$ ) (Sallamand \& Pelletier, 1993) 


\section{Laser shock peening of aluminium alloys}

Laser shock peening (LSP) is an innovative surface treatment technique, which is successfully applied to improve fatigue performance of metallic components. After the treatment, the fatigue strength and fatigue life of a metallic material can be increased remarkably owing to the presence of compressive residual stresses in the material. The increase in hardness and yield strength of metallic materials is attributed to high density arrays of dislocations and formation of other phases or twins, generated by the shock wave.

The ability of a high energy laser pulse to generate shock waves and plastic deformation in metallic materials was first recognised and explored in 1963 in the USA (Ding \& Ye, 2006). A schematic configuration of an LSP process on a workpiece is shown in figure 36 (Dubourg et al., 2005).

When shooting an intense laser beam on to a metal surface for a very short period of time (around $30 \mathrm{~ns}$ ), the heated zone is vaporised to reach temperatures in excess of $10000^{\circ} \mathrm{C}$ and then is transformed to plasma by ionisation. The plasma continues to absorb the laser energy until the end of the deposition time. The pressure generated by the plasma is transmitted to the material through shock waves (Ding \& Ye, 2006). Although metals can be highly reflective of light, keeping the constant laser power density and decreasing the wavelength from IR to UV can increase the photon-metal interaction enhancing shock wave generation. However, the peak plasma pressure may decrease because decreasing the wavelength decreases the critical power density threshold for a dielectric breakdown, which in turn limits the peak plasma pressure. The dielectric breakdown is the generation of plasma not on the material surface, which absorbs the incoming laser pulse, limiting the energy to generate a shock wave. In Figure 37, the decrease in the wavelength from IR to green reduces the dielectric breakdown threshold from $10-6 \mathrm{GW} / \mathrm{cm}^{2}$, resulting in maximum peak pressures of approximately 5.5 and 4.5GPa, respectively (Ding \& Ye, 2006).

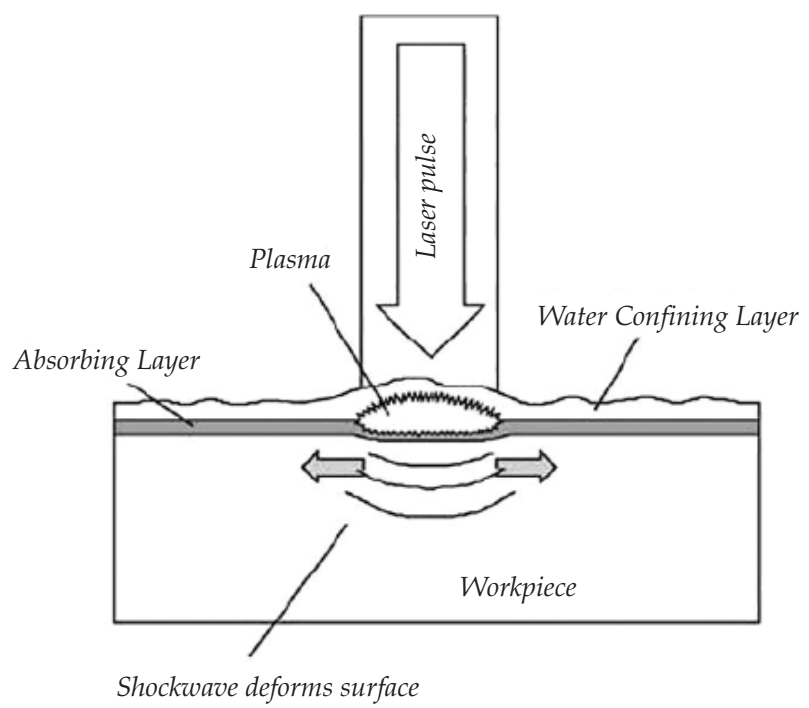

Fig. 36. Schematically principle of laser shock processing (Ding \& Ye, 2006) 
The transmission of an incident laser pulse throughout a water layer is expected to be controlled significantly by its pulse duration and / or to its rise time. Indeed, the faster energy deposition may generate the better laser-target coupling in plasma confined regime with water (Peyre et al., 2005).

Payer et al. (Peyre et al., 2005) studies the influence of laser intensity, wavelength, and pulse duration on the pressures generated in plasma. Results are presented in figures 38, 39.

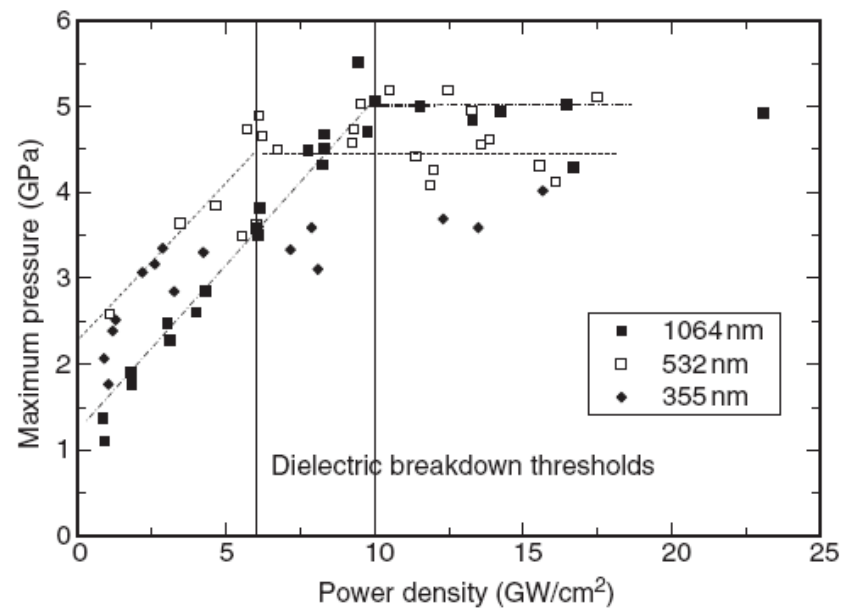

Fig. 37. Peak plasma pressures obtained in WCM as a function of laser power density at $1.064 \mathrm{~mm}, 0.532 \mathrm{~mm}$ and $0.355 \mathrm{~mm}$ laser wavelength (Ding \& Ye, 2006)

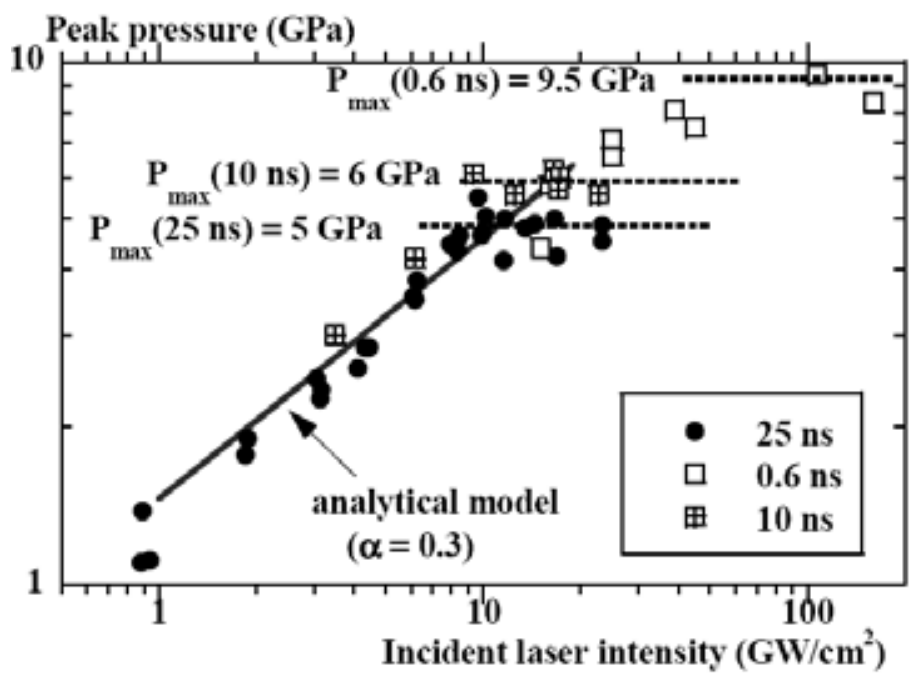

Fig. 38. Influence of laser intensity and pulse durations on the pressures generated in plasma confined with water regime $(\lambda=1.06 \mu \mathrm{m})$-compaison with the analytical model of confinement (25 ns) (Peyre et al., 2005) 


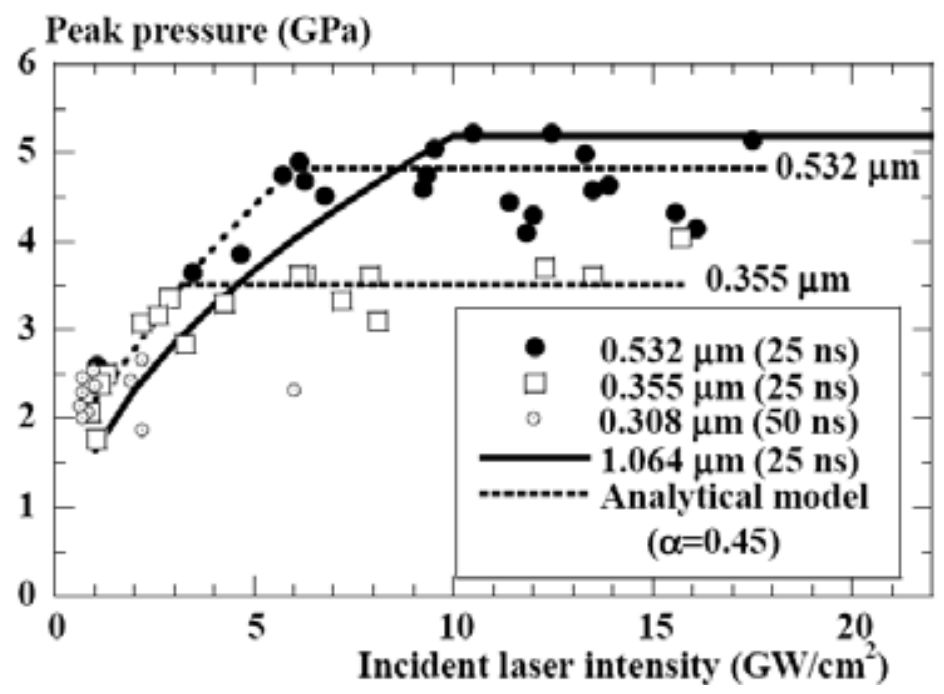

Fig. 39. Influence of laser wavelength on the pressures generated in plasma confined regime with water (all measurements performed at $25 \mathrm{~ns}$ pulse durations except $0.308 \mu \mathrm{m}$ at $50 \mathrm{~ns}$ ) (Peyre et al., 2005)

It can be seen that the maximum available pressure was saturated to nearly 5-6 GPa above 8$10 \mathrm{GW} / \mathrm{cm}^{2}$ laser intensity (Fig.1). This saturation was shown to occur because of a parasitic breakdown plasma at the surface of the water which effect was to limit the energy reaching the target and cut temporally the incident laser pulse, thus reducing its effective duration 8 . These pressure levels are usually sufficient to harden all the metallic materials but, most of times, impact sizes need to be reduced to reach the convenient power densities (Peyre et al., 2005). Also, the first conclusion to draw from these results is that pressure saturation levels increase with shorter laser pulse durations: from 5-5.5 GPa at $25 \mathrm{~ns}$ to $6 \mathrm{GPa}$ at $10 \mathrm{~ns}$ and 9.5$10 \mathrm{GPa}$ at $0.6 \mathrm{~ns}$. At shorter durations, the pressure saturation occurs at much higher laser intensity ( $\mathrm{I}_{\text {th }}=$ around $100 \mathrm{GW} / \mathrm{cm}^{2}$ versus $10 \mathrm{GW} / \mathrm{cm}^{2}$ at $\left.10-30 \mathrm{~ns}\right)$. This clearly indicates that energy transmissions through the water thickness are improved and that deleterious effects from breakdown plasmas are reduced by the use of shorter durations (Peyre et al., 2005). As can be seen from figure 39 Maximum output pressures $P_{\max }$ and intensity thresholds $\mathrm{I}_{\text {th }}$ tend to be reduced with decreasing wavelengths. At the same pulse duration, maximum pressures decrease from $5.5 \mathrm{GPa}$ at $1.06 \mu \mathrm{m}$ to $5 \mathrm{GPa}$ at $0.532 \mu \mathrm{m}$ and $3.5 \mathrm{GPa}$ at $0.355 \mu \mathrm{m}$. Intensity thresholds in the UV regime are also reduced to nearly $4 \mathrm{GW} / \mathrm{cm}^{2}$ versus $10 \mathrm{GW} / \mathrm{cm}^{2}$ at $1.06 \mu \mathrm{m}$. Moreover, the pressure durations (and in turn the transmitted laser pulse durations) decrease much more drastically above the intensity thresholds at lower wavelength. Also, at low intensity $\left(1-4 \mathrm{GW} / \mathrm{cm}^{2}\right)$ the efficiency of the pressure generation is shown to be improved at $0.532 \mu \mathrm{m}$ and $0.355 \mu \mathrm{m}$. Indeed, according to the analytical model of confinement, the " $\alpha$ " coefficient gives a good fitting with experimental measurement with $\alpha=0.45$ versus $\alpha=0.3$ in the IR configuration). This could be due to a better target-plasma absorption in the UV range (Peyre et al., 2005). LSP generates compressive residual stresses (CRS) which are known to be the key to enhanced surface Properties (Ding \& Ye, 2006). 
Residual stresses increase with increasing laser induced pressures until a given pressure level called Psat where a plastic saturation occurs and above which CRS remain nearly constant. Below HEL (Hugoniot Elastic Limit), no plastic deformation occurs and in turn no residual stresses. Maximum RS levels induced by LSP are close to $-0.5 \sigma_{Y}$ for one local deformation and $-0.7 \sigma_{Y}$ for numerous ones (Figure 40) (Ding \& Ye, 2006).

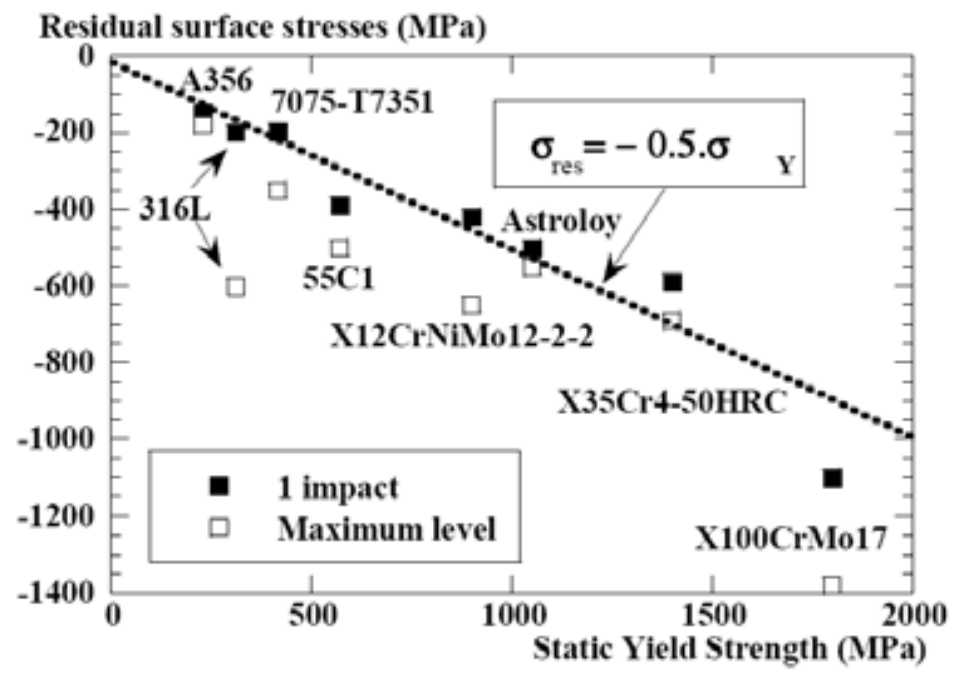

Fig. 40. Influence of the mechanical properties of the targets on the residual stress levels achievable by LSP - Results taken from (Aluminium alloys), (Astroloy Ni superalloy), (X100CrMo17) , (316L and X12CrNiMo12-2-2) (Ding \& Ye, 2006)

Many recent studies have evidenced the beneficial influence of LSP on mechanical cyclic properties. On cast and wrought aluminium alloys (Al-7Si and Al12Si, 7075), some 25 to 40 $\%$ fatigue limit increases were displayed on notched specimens submitted to $\mathrm{R}=0.1$ bending loadings. These results, superior to shot-peening ( $+25 \%$ versus $+12 \%$ on 7075$)$ were shown to be due to some large improvements in the fatigue crack initiation stage (Peyre et al., 1996).

Lu et al. (Lu et al., 2010) studied the effect of laser shock peening on properties of aluminum alloys. In their report, the residual stress profiles of the treated samples after multiple LSP impacts with the impact time as functions of the distance from the top surface are shown in Figure 41. The substrates are approximately in the zero-stress state, indicating that the effect of initial stress on the shock waves may be ignored (Tan et al., 2004). It can be noted from Figure 41 that the significant compressive residual stresses mainly exist in near-surface regions for all cases and the top surfaces have the maximum values of compressive residual stresses (Lu et al., 2010).

The peak surface compressive residual stress and the depth of compressive residual stress are significantly increased to $116 \mathrm{MPa}$ and to $0.79 \mathrm{~mm}$, respectively, as a result of $3 \mathrm{LSP}$ impacts on the sample surface. After 4 LSP impacts, the peak value of surface compressive residual stress is increased to $123 \mathrm{MPa}$, and the depth of compressive residual stress reaches about $0.80 \mathrm{~mm}$. It can be seen that the surface compressive residual stress is increased by 
$25.93 \%$ and $13.73 \%$ when the impact time increases from 1 to 2 and from 2 to 3 , whereas the surface compressive residual stress is increased by $6.89 \%$ when the impact time increases from 3 to 4 , but the surface compressive residual stress is kept to about $123 \mathrm{MPa}$ after the multiple LSP with 4 and 5 LSP impacts (Lu et al., 2010). It can be seen from Figure 42 that the increasing rate of surface compressive residual stress decreases almost linearly with the impact time, but the increase of surface residual stresses gradually reaches the saturated state when the impact time exceeds 4 . The similar results can be seen elsewhere (Masse \& Barreau, 1995; Ding \& Ye, 2003).

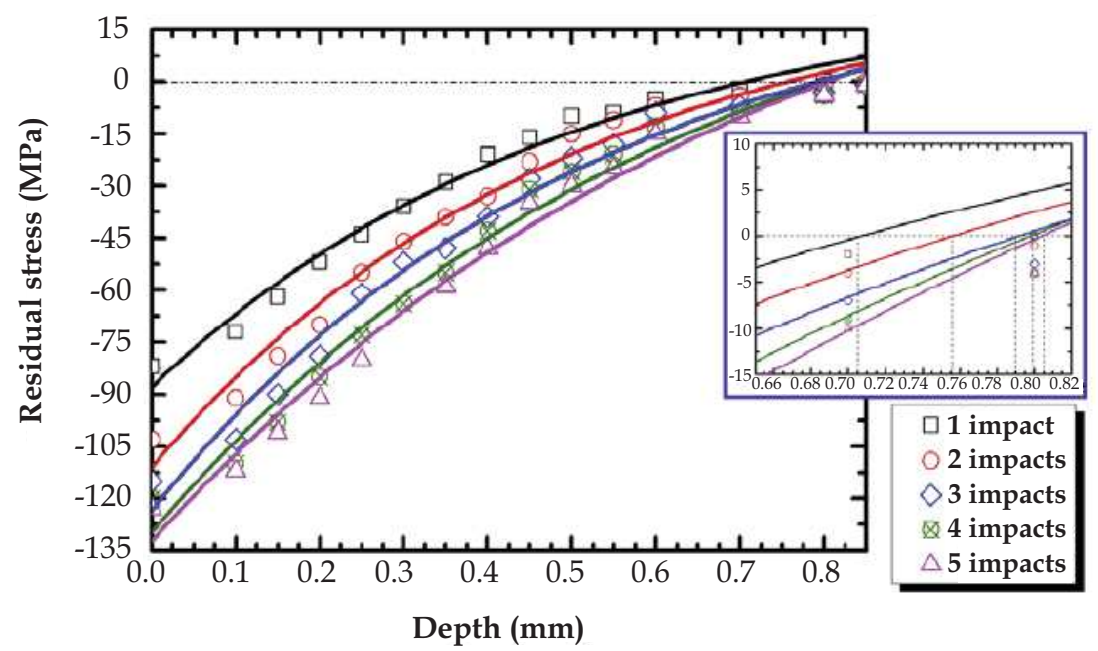

Fig. 41. Residual stress profiles of the hardening layer after multiple LSP impacts with the impact time (Lu et al., 2010)

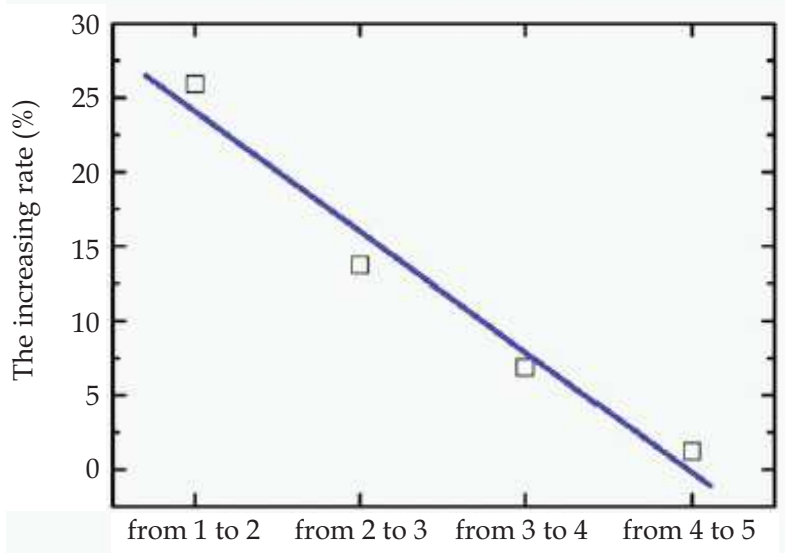

Fig. 42. The comparison between the increasing rate of surface residual stress and the impact time (Lu et al., 2010) 


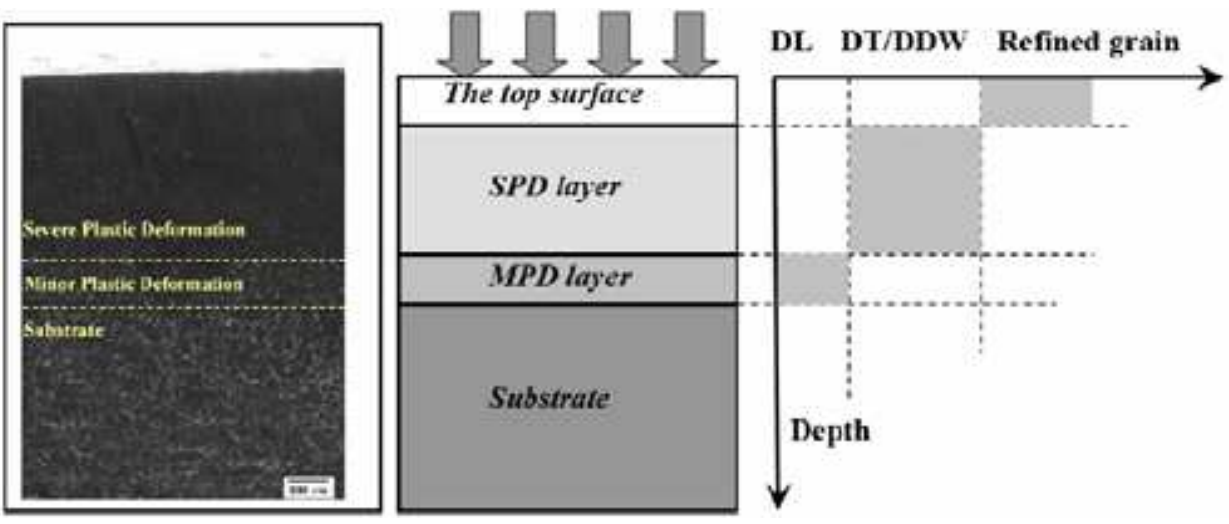

Fig. 43. Schematic illustrations of micro-structure characteristics along depth direction in the hardening layer subjected to 3 LSP impacts (Lu et al., 2010)

It is well known that residual stresses in metal materials are often the result of micro-plastic deformation accompanying the micro-structure changes (Yilbas \& Arif, 2007). As a result, it is reasonable to assume that the LSP induced strengthening in metal materials is due to the generation of dislocations. The schematic illustrations of the micro-structure characteristics of the hardening layer subjected to 3 LSP impacts are shown in Figure 43. After 3 LSP impacts, the change of dislocation structure can be also clearly seen at different layers, i.e., it varies from DLs to DTs and DDWs, to subgrains or refined grains as functions of the distance from the top surface. After multiple LSP impacts, the grains in the SPD layer are clearly refined and there are plenty of DLs and DTs with high density in the SPD layer. As a result of the grain refinement, the shocked area is strengthened according to the classical dislocation theory (Chen et al., 2003), where

$$
\begin{gathered}
\tau_{N}=\frac{2 \alpha \mu b_{N}}{D} \\
\tau_{p}=\frac{2 \alpha \mu b_{p}}{D}+\frac{\gamma}{b_{p}}
\end{gathered}
$$

Here $\mu$ is the shear modulus ( $\sim 35 \mathrm{GPa}$ for $\mathrm{Al}$ alloy), $\gamma$ is the stacking fault energy (104-142 $\mathrm{mJ} \mathrm{m}^{-2}$ for $\mathrm{Al}$ alloy (Lu et al., 2010)), $\mathrm{D}$ is the grain size, and $\mathrm{b}_{\mathrm{N}}$ and $\mathrm{b}_{\mathrm{P}}$ are the magnitudes of the Burgers vectors of the perfect dislocation and the Shockley partial dislocation, respectively. The parameter $\alpha$ reflects the character of the dislocation and contains the scaling factor between the length of the dislocation source and the grain size.

The grain boundaries are taken as dislocation sources, as predicted by computer simulations for subgrains or refined grains. When the grain size becomes smaller than a critical value, $\mathrm{D}_{\mathrm{C}}$, determined by equating Eqs. (13) and (14),

$$
D_{c}=\frac{2 \alpha \mu\left(b_{N}-b_{p}\right) b_{p}}{\gamma}
$$

The generation of subgrain interfaces and stacking faults offers an alternative interpretation to dislocation pile-up at grain boundaries to explain the continuous grain-size 
strengthening, as suggested by Eq. (14), and the strain hardening of the metal materials. The reaction between the laser shock wave and the sample will be generated near the sample surface, leading to the generation of the dislocation and the micro-structural deformation near the surface, which can be explained by the fact that the compressive residual stresses are generated in the PD layer, and the magnitude of the compressive residual stress decreases away from the top surface.

The grain refinement mechanism is schematically illustrated in figure 44 . Based on the micro-structure features observed in various layers with different strains in the hardening layer, the following elemental states are involved in the grain refinement process: (1) development of DLs in original grains (state (I) in figure 44); (2) the formation of DTs and DDWs due to the pile-up of DLs (state (II) in figure 44); (3) transformation of DTs and DDWs into subgrain boundaries (state (III) in figure 44); and (4) evolution of the continuous dynamic recrystallization (DRX) in subgrain boundaries to refined grain boundaries (states (IV) and (V) in figure 44).

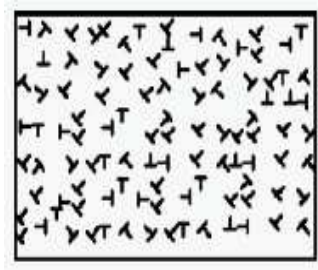

(a) Dislocation

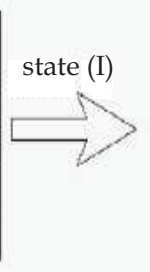

(b)

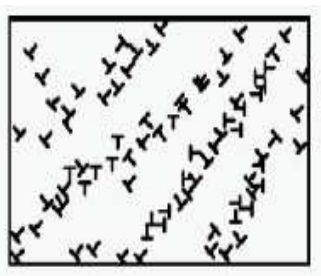

Dislocation lines

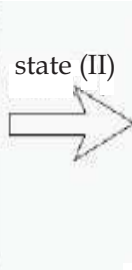

(c)

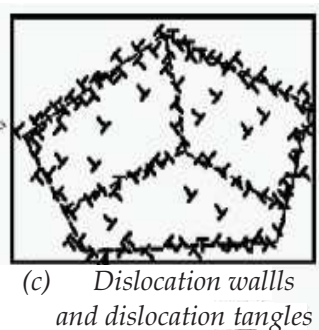

and dislocation tangles

state (III)

(d) Subgrains

(e) DRX nucleation

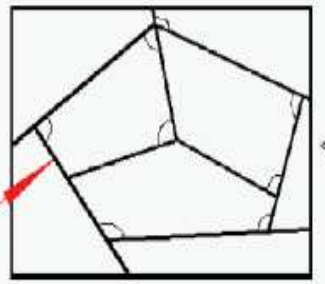

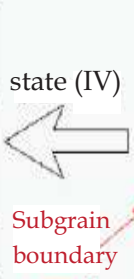

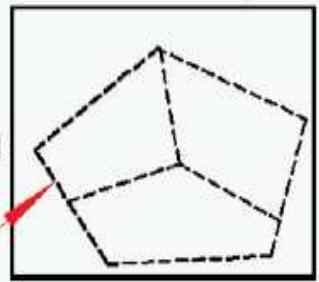

Fig. 44. Schematic illustration showing micro-structural evolution process of LY2 Al alloy induced by multiple LSP impacts (Lu et al., 2010)

The comparison of effect sot peening and laser sock peening on fatigue behavior of Al- alloy was investigated by Gao (Gao, 2011). To determine the effect of surface enhancement on fatigue property and get the optimum parameters, the FLPF analysis under the same stress load or strain load conditions is usually employed. The FLPF is calculated as:

$$
F L P F=\frac{N_{\text {modifiedspecimen }}}{N_{\text {baselinespecimen }}}-1
$$

For the different surface conditions, the fatigue lives of specimens and FLPF are listed in Table 2. 


\begin{tabular}{llll}
\hline Surface treatment & Minimum fatigue life & Maximum fatigue life & Average fatigue life \\
\hline Machined baseline & $2.41 \times 10^{4}$ & $2.69 \times 10^{4}$ & $2.55 \times 10^{4}$ \\
SP-GB150 & $5.18 \times 10^{4}$ & $5.52 \times 10^{4}$ & $5.49 \times 10^{4}$ \\
SP-S110 & $4.74 \times 10^{4}$ & $5.27 \times 10^{4}$ & $4.84 \times 10^{4}$ \\
SP-Z150 & $8.84 \times 10^{4}$ & $9.46 \times 10^{4}$ & $9.23 \times 10^{4}$ \\
SP-S110+Z150 & $8.65 \times 10^{4}$ & $9.21 \times 10^{4}$ & $8.97 \times 10^{4}$ \\
SP-S110+GB150 & $1.15 \times 10^{5}$ & $1.24 \times 10^{5}$ & $1.19 \times 10^{5}$ \\
LP- $N=2$ & $9.19 \times 10^{4}$ & $1.15 \times 10^{5}$ & $9.92 \times 10^{4}$ \\
LP- $N=4$ & $1.52 \times 10^{5}$ & $2.14 \times 10^{5}$ & $1.94 \times 10^{5}$ \\
LP-N=6 & $1.46 \times 10^{5}$ & $1.91 \times 10^{5}$ & 2.620 \\
LP- $N=8$ & $9.54 \times 10^{4}$ & $1.08 \times 10^{5}$ & $3.65 \times 10^{5}$ \\
\hline
\end{tabular}

Table 2. Fatigue lives of specimens and FLPF under 300MPa stress (Gao, 2011)

The compressive residual stress distribution along surface layer for laser-peened and shotpeened specimens under different regimes are shown in Figures 45, 46.

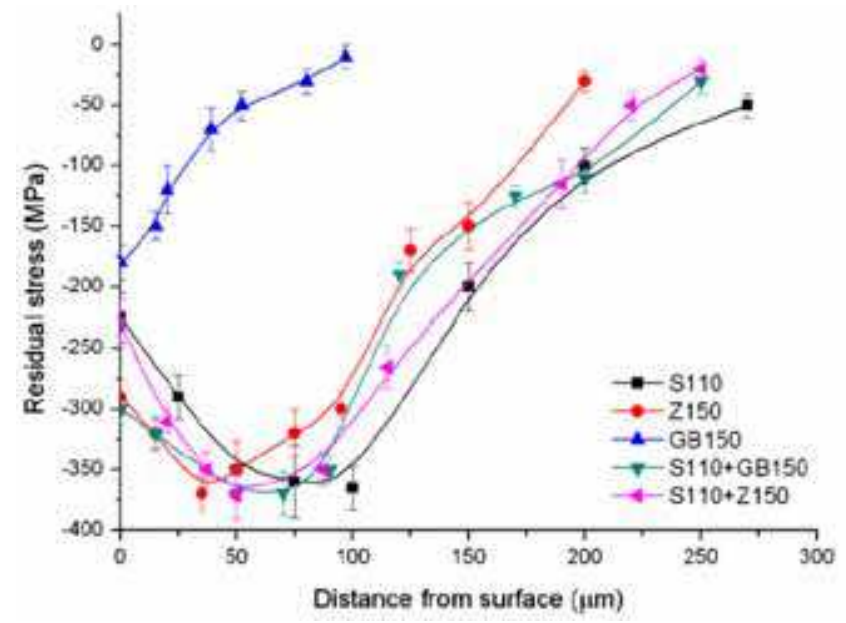

Fig. 45. Compressive residual stress field caused by shot peening (Gao, 2011)

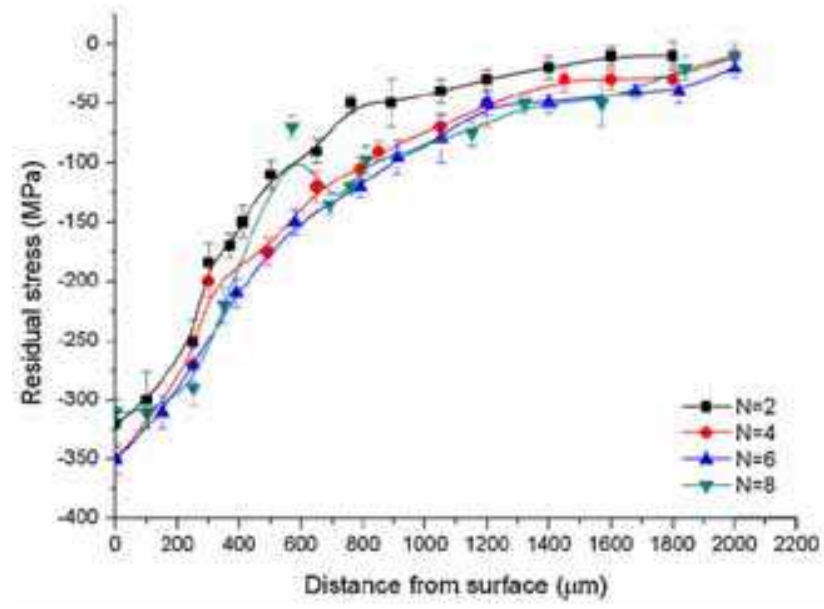

Fig. 46. Compressive residual stress field caused by laser peening (Gao, 2011) 
The fatigue strength for $1 \times 107$ cycles of 7050-T7451 aluminum alloy was increased by shot peening and laser peening. Fatigue strength of the best-laser-peened specimens is $42 \%$ higher than as-machined specimens and the fatigue strength of the best shot-peened specimens is $35 \%$ higher than as-machined (Gao, 2011).

\section{References}

Aleksandrov, V. D. (2002). Modification of the surface of aluminium alloys by laser treatment", Metal Science and Heat Treatment, vol. 44, No.3-4, pp.168-171.

Almeida, A., Petrov, P., Nogueira, I., \& Vilar, R. (2001). Structure and properties of Al-Nb alloys produced by laser surface alloying. Materials Science and Engineering A, Vol. 303, pp.273-280.

Anandkumar, R., Almeida, A., Colaco, R., Vilar, R., Ocelik, V., Th, d, \& De Hosson, M. (2007). Microstructure and wear studies of laser clad Al-Si /SiC composite coatings. Surface and Coating Technology, Vol. 201, pp. 9497-9505.

Anandkumar, R., Almeida, A., Vilar, R., Ocelík, V., \& De Hosson, J.Th.M. (2009). Influence of powder particle injection velocity on the microstructure of Al-12Si/SiCp coatings produced by laser cladding. Surface \& Coatings Technology, Vol. 204, pp. 285-290.

Chen, M. W., Ma, E., Hemke, K. J., Sheng, H. W., Wang, Y. M., Cheng, X. M. (2003). Deformation Twinning in Nanocrystalline Aluminum. Science, Vol. 300, pp.12751277.

Chong, P.H., Liu, Z., Skeldon, P., \& Thompson, E. (2003). Corrosion behavior laser surface melted 2014 aluminium alloy in T6 and T451 tempers. The journal of corrosion science and engineering, Vol. 6, paper 12.

Costa, L. \& Vilar, R. (1996). Diffusion-limited layer growth in spherical geometry: A numerical approach. eburnal of Applied Physics, Vol. 80, No. 8, pp.4350-4353.

Damborenea, J. de. (1998). surface modification of metals by power lasers. Surface coatings technology, Vol. 100-101, pp.377-382.

Ding, K., \& Ye, L. (2003). Three-dimensional Dynamic Finite Element Analysis of Multiple Laser Shock Peening Processes. Surface Engineering, Vol. 19, p.351-358.

Ding, K. \& Ye, L. (2006). Laser shock peening Performance and process simulation. Woodhead Publishing Limited, USA.

Draper, C. W., \& Poate, J. M. (1985). Laser surface alloying. International Metals Reviews, Vol. 30, pp. $85-108$.

Dubourg, L., Ursescu, D., Hlawka, F., \& Cornet, A. (2005). Laser cladding of MMC coatings on aluminium substrate: influence of composition and microstructure on mechanical properties. Wear, Vol. 258, pp. 1745-1754.

Fu, Y.C., Loredo, A., Martin, B., \& Vannes, A.B. (2002). A theoretical model for laser and powder particles interaction during laser cladding. Journal of Materials Processing Technology, Vol. 128, pp. 106-112.

Gao, Y. K. (2011). Improvement of fatigue property in 7050-T7451 aluminum alloy by laser peening and shot peening. Materials Science and Engineering, Vol. A528, pp. 38233828

Gingu, O., Mangra, M., \& Orban, R. L. (1999). In-Situ production of Al/SiCp composite by laser deposition technology. eburnal of Materials Processing Technology, Vol. 89-90, pp.187-190. 
Guillaumin, V., \& Mankowski, G. (1999). Localized corrosion of 2024 T351 aluminium alloy in chloride media. Corrosion Science, Vol. 41, pp.421-438.

$\mathrm{Hu}, \mathrm{C} ., \mathrm{Xin}$ H., \& Baker, T.N. (1996). Formation of continuous surface Al-SiCp metal matrix composite by overlapping laser tracks on AA6061 alloy. Materials Science and Technology, Vol. 12, pp. 227-232.

Huang, Y.L., Liang, G.Y., Su, J. Y., \& Li, J.G. (2005). Interaction between laser beam and powder stream in the process of laser cladding with powder feeding. Model Simul. Mater. Sci. Vol. 13, pp.47-56.

Jouvard, J.M., Grevey, D.F., Lemoine, F., \& Vannes, A.B. (1997). Continuous Wave Nd:YAG Laser Cladding Modeling: A Physical Study of Track Creation During Low Power Processing. Journal of Laser Application, Vol. 9, pp. 43-50.

Leech, P. W. (1989). The Laser Surface Melting of Aluminium-Silicon-Based Alloys. Thin Solid Films, Vol. 177, pp. 133140.

Li, R., Ferreira, M.G.S., Almeida, A., Vilar, R., Watkins, K. G., McMahon, M.A., \& Steen, W.M. (1996). Localized corrosion of laser surface melted 2024-T351 aluminium alloy. Surface and coatings technology, Vol. 81, pp.290-296.

Lu, J.Z., Luo, K.Y., Zhang, Y.K., Cui, C.Y., Sun, G.F., Zhou, J.Z., Zhang, L., You, J., Chen, K.M., \& Zhong, J.W. (2010). Grain refinement of LY2 aluminum alloy induced by ultra-high plastic strain during multiple laser shock processing impacts. Acta Materialia, Vol. 58, pp. 3984-3994.

Majumdar, D. J. \& Manna, I. (2002). A Theoretical Model for Predicting Microstructure during Laser Surface Alloying. Lasers in Engineering, Vol. 12, pp. 171-190.

Masse, J. E., \& Barreau, G. (1995). Surface modification by laser induced shock waves. Surface Engineering, Vol. 11, p.131-132.

Munitz, A. (1985). Microstructure of rapidly solidified laser-molten Al- 4.5 wt \% Cu surfaces. Metall Trans B, Vol. 16, pp.149- 161.

Nagarathnam, K. \& Taminger, K.M.B. ( 2001). Technology Assessment of Laser-Assisted Materials Processing in Space. CP 552, Space Technology and Applications International Forum, paper edited by M.S. El-Genk, pp. 153-160.

Peyre, P., Fabbro, R., Berthe, L., Scherpereel, X., \& Bartnicki, E. (2005). Laser shock processing of materials and related measurements", CLFA/LALP, 94114 Arcueil, France.

Peyre, P., Fabbro, R., Merrien, P., \& Lieurade, H.P. (1996). Laser shock processing of aluminium alloys. Application to high cycle fatigue behavior. Materials Science \& Engineering, Vol. A210, pp.102-113.

Pinto, M. A., Cheung, N., Ierardi, M.C.F., Garcia, A. (2003). Microstructural and hardness investigation of an aluminum-copper alloy processed by laser surface melting. Materials Characterization, Vol. 50, pp. 249- 253.

Rams, J., Padro, A., Urena, A., Arrabal, R., Viejo, F., \& Lopez, A.J. (2007). Surface treatment of aluminium matrix composites using a high power diod laser. Surface and Coatings Vol. 202, pp. 1199-1203

Technology,

Renk, T. J., Buchheit, R. G., Sorensen, N. R., Cowell Senft, D., Thompson, M. O., \& Grabowski, K. S. (1998). Improvement of surface properties by modification and alloying with high-power ion beams", Phys. Plasmas, Vol. 5, pp. 2144-2150.

Sallamand, P., \& Pelletier, J. M. (1993). Laser cladding on aluminium-base alloys: microstructural features", Materials Science and Engineering, Vol. A 171, pp. 263-270. 
Senthil Selvan, J., Soundararajan, G., \& Subramanian, K. (2000). Laser alloying of aluminium with electrodeposited nickel: optimisation of plating thickness and processing parameters. Surface and Coatings Technology, Vol. 124, pp. 117-127.

Tan, Y., Wu, G., Yang, J. M., \& Pan, T. (2004). Laser shock peening on fatigue crack growth behaviour of aluminium alloy. Fatigue Fracture Engineering and Materials Structure, Vol. 27, pp.649-656.

Tomlinson W.J. \& Bransden A.S. (1996). Cavitation erosion of laser surface alloyed coatings on $\mathrm{Al}-12 \% \mathrm{Si}^{\prime \prime}$, International Journal of Multiphase Flow, Vol. 22, No. 1, pp. 152-152.

Tomida, S., Nakata, K. (2003). Fe-Al composite layers on aluminum alloy formed by laser surface alloying with iron powder. Surface and Coatings Technology, Vol. 174-175, pp. 559-563.

Viala, J.C., Fortier, \& Bouix, P. (1990). Stable and metastable phase equilibria in the chemical interaction between aluminium and silicon carbide. eburnal of Materials Science, Vol. 25, pp. 1842-1850.

Wong, T.T., Liang, G.Y., Tang, C.Y. (1997). The surface character and substructure of aluminum alloys by laser-melting treatment", cburnal of materials processing Technology, Vol. 66, pp.172-178.

Wong, T.T., \& Liang, G.Y. (1997). Effect of laser melting treatment on the structure and corrosion behavior of aluminium and Al-Si alloys. eburnal of Materials Processing Technology, Vol. 63, pp.930-934.

Xu, W.L., Yue, T.M., Man, H.C., \& Chan, C.P. (2006). Laser surface melting of aluminium alloy 6013 for improving pitting corrosion fatigue resistance. Surface \& Coatings Technology, Vol. 200, pp. 5077-5086.

Yilbas, B. S., Arif AFM , (2007). Laser shock processing of aluminium: model and experimental study. J Phys D, Appl Phys 40, pp.6740-6747.

Yongqing, F., Batchelor, A.W., Yanwei, G., Khor, K.A., \& Huting X. (1998). Laser alloying of aluminum alloy AA 6061 with $\mathrm{Ni}$ and Cr. Part 1. Optimization of processing parameters by X-ray imaging. Surface and Coatings Technology, Vol. 99, pp. 287-294.

Yue, T. M., Yan, L.J., Chan, C.P., Dong, C.F., Man, H.C., \& Pang, G.K.H. (2004). Excimer laser surface treatment of aluminium alloy AA7075 to improve corrosion resistance. Surface and Coatings Technology, Vol. 179, No. 2-3, pp.158-164.

Zimmermann, M., Carrard, M., Kurz, W. (1989). Rapid solidification of Al -Cu eutectic alloy by laser remelting. Acta Metallurgica, Vol. 37, No. 12, pp.3305-13. 


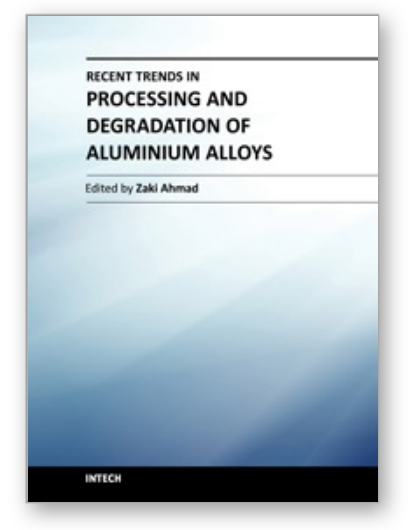

\section{Recent Trends in Processing and Degradation of Aluminium Alloys \\ Edited by Prof. Zaki Ahmad}

ISBN 978-953-307-734-5

Hard cover, 516 pages

Publisher InTech

Published online 21, November, 2011

Published in print edition November, 2011

In the recent decade a quantum leap has been made in production of aluminum alloys and new techniques of casting, forming, welding and surface modification have been evolved to improve the structural integrity of aluminum alloys. This book covers the essential need for the industrial and academic communities for update information. It would also be useful for entrepreneurs technocrats and all those interested in the production and the application of aluminum alloys and strategic structures. It would also help the instructors at senior and graduate level to support their text.

\section{How to reference}

In order to correctly reference this scholarly work, feel free to copy and paste the following:

Reza Shoja Razavi and Gholam Reza Gordani (2011). Laser Surface Treatments of Aluminum Alloys, Recent Trends in Processing and Degradation of Aluminium Alloys, Prof. Zaki Ahmad (Ed.), ISBN: 978-953-307-734-5, InTech, Available from: http://www.intechopen.com/books/recent-trends-in-processing-and-degradation-ofaluminium-alloys/laser-surface-treatments-of-aluminum-alloys

\section{INTECH}

open science | open minds

\section{InTech Europe}

University Campus STeP Ri

Slavka Krautzeka 83/A

51000 Rijeka, Croatia

Phone: +385 (51) 770447

Fax: +385 (51) 686166

www.intechopen.com

\section{InTech China}

Unit 405, Office Block, Hotel Equatorial Shanghai

No.65, Yan An Road (West), Shanghai, 200040, China

中国上海市延安西路65号上海国际贵都大饭店办公楼 405 单元

Phone: +86-21-62489820

Fax: +86-21-62489821 
(C) 2011 The Author(s). Licensee IntechOpen. This is an open access article distributed under the terms of the Creative Commons Attribution 3.0 License, which permits unrestricted use, distribution, and reproduction in any medium, provided the original work is properly cited. 